\title{
Atomic and molecular layer deposition in pursuing better batteries
}

\author{
Xiangbo Menga) \\ Department of Mechanical Engineering, University of Arkansas, Fayetteville, Arkansas 72701, USA \\ a) e-mail: xbmeng@uark.edu \\ Received: 30 May 2020; accepted: 16 June 2020
}

In the past decade, atomic and molecular layer deposition (ALD and MLD), these two sister techniques have been attracting more and more research attention to address technical challenges in various advanced battery systems. The charm of both ALD and MLD lies in their unique mechanism for growing a large variety of functional materials, featuring uniform and conformal films enabled at the atomic/molecular level at low temperature. Using ALD and MLD, to date, there have been many excitements achieved in research. These will ultimately be reflected on technical innovations that will help revolutionize our lifestyles. This invited article gives the first comprehensive review briefing on the journey of ALD and MLD in pursuing better batteries and highlighting many exciting progresses in various advanced battery systems. It is expected that this review will help boost many more efforts in using ALD and MLD for new battery technologies in the coming decade.

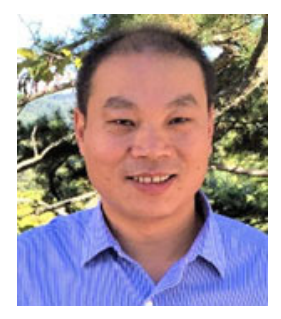

\begin{abstract}
Xiangbo Meng is currently an Assistant Professor in Department of Mechanical Engineering at the University of Arkansas (Fayetteville, AR). He received one PhD degree in Mechanical \& Materials Engineering (2011) with Prof. Andy Sun and another in Chemical \& Biochemical Engineering (2008) with Prof. Jesse Zhu, both from the University of Western Ontario (ON, Canada). Prior to joining the University of Arkansas in 2016, he was a Research Fellow (2012-2016) in Energy Systems Division at Argonne National Laboratory (Lemont, IL) with Dr. Jeffrey W. Elam and a Research Associate (2011-2012) in Chemistry Department at Brookhaven National Laboratory (Upton, NY) with Dr. Xiao-Qing Yang. He was the recipient of a Canada NSERC Postdoctoral Fellowship (2011-2013), the AVS Student Award in ALD (2011), and the $2^{\text {nd }}$ Prize of OCE Competition (2008). He also was the nominee of Canadian CGS/UMI Distinguished Dissertation Award (2009) and Moore Inventor Fellows (2017). His interests lie in smartly designing novel nanostructured materials for a wide range of applications such as energy, catalysis, semiconductors, surface engineering, and biomedical. Currently, Dr. Meng's research focuses on developing new chemical processes for growing new inorganic, organic, and hybrid nanomaterials in a precisely controllable mode using both atomic and molecular layer deposition (ALD and MLD), and on developing high-performance advanced battery systems, including lithium-ion batteries, lithium-sulfur batteries, sodium-ion batteries, solid-state batteries, and microbatteries.
\end{abstract}

\section{Introduction}

Nowadays, batteries have become a commodity related to national and strategic significance [1]. They are essential for widely implementing renewable clean energies (such as solar and wind powers). The latter suffers from the intermittent operation and needs electrical energy storage (EES) devices to store electricity in the form of chemical energy. Given the facts that fossil fuels are continuously depleting and causing a series of environmental issues related to their combustion, renewable clean energies are highly regarded as promising alternatives and can be the potential game changers. To this end, batteries as one of the most successful EES devices can store electrical energy from the renewables and then supply it whenever and wherever there is a need. To date, batteries have potentials to suffice three main domains: portable electronics (e.g., laptops and cell phones), transportation (e.g., electric vehicles and hybrid electric vehicles), and electric grids.

In terms of rechargeability, batteries can be either primary or secondary. A primary battery cell is not reusable once exhausted, while a secondary battery cell can provide electrical energy during discharge and then be restored to its original charged condition through an electric current flowing in the 
opposite direction of discharge (i.e., charge) [2]. Thus, secondary batteries also are called rechargeable batteries. The first rechargeable battery is the lead-acid battery invented by Gaston Plante in 1859, followed by nickel-cadmium (1899), nickel-metal hydride (NiMH, the mid-1980s), and lithium-ion batteries (LIBs) that were conceptualized in the 1970s and commercialized by Sony Co. (Tokyo, Japan). in 1991 [3, 4, 5]. In developing these rechargeable batteries, higher energy density has been one of the main pursuits. State-of-the-art LIBs, for instance, can realize an energy density of $\sim 250 \mathrm{Wh} / \mathrm{kg}$, which is over six times higher than that of the lead-acid battery [5, 6 , 7]. As a return, the LIB cells can be downsized and the revolutionization of LIBs has led to their dominance in consumer electronics. As the most successful EES devices developed so far, LIBs are further expected to electrify our future transportation and to support smart grids. To accomplish these tasks, however, state-of-the-art LIBs are still not sufficient in several ways. In order to widely commercialize electric vehicles (EVs), specifically, it is imperative to develop next-generation LIBs enabling to satisfy the following requirements: a highenergy density of $\geq 300 \mathrm{Wh} / \mathrm{kg}$ for a driving range of $\geq 300$ miles, an affordable cost of $\leq \$ 125 / \mathrm{kWh}$, reliable safety free of fires and explosions, and a long lifetime of $\geq 15$ calendar years $[8,9]$. To this end, new materials and new designs are urgently needed. For instance, researchers are seeking highercapacity cost-effective electrodes [e.g., silicon anodes and $\mathrm{LiNi}_{x} \mathrm{Mn}_{y} \mathrm{Co}_{z} \mathrm{O}_{2}$ (NMC) cathodes, which enable to store more lithium ions per unit volume or mass] to replace the present ones [e.g., graphite anodes and $\mathrm{LiCoO}_{2}$ (LCO) cathodes] for next-generation LIBs of higher energy density and lower cost [1, 7]. In addition, solid-state electrolytes (SEs) are under development in order to substitute traditional organic liquid electrolytes (oLEs) for the sake of safety concerns [10]. Beyond LIBs, in addition, new battery systems also have been proposed and undergoing intensive investigation, such as lithium-sulfur ( $\mathrm{Li}-\mathrm{S})$, lithium-oxygen $\left(\mathrm{Li}-\mathrm{O}_{2}\right)$, and sodium-ion batteries (SIBs). In all these advanced battery systems, their interfaces are playing a vital role in determining their electrochemical performance and should be specially designed [11, 12]. Thus, there are many efforts needed for better batteries. In this regard, atomic and molecular layer deposition (ALD and MLD) $[13,14]$ have emerged as two new thrusts in the past decade, featuring their unique capabilities in materials growth at the atomic/molecular scale. Research attempts of both ALD and MLD were first witnessed in LIBs [15, 16] and then greatly widened into SEs [17] and beyond Li-ion batteries (e.g., $\mathrm{Li}-\mathrm{S}$ [18], $\mathrm{Li}-\mathrm{O}_{2}$ [19], and SIBs [20]). Thus, there has been an ever-increasing interest in using both ALD and MLD for pursuing better batteries.

In this review, we devote to make the first effort to outline the main achievements of ALD and MLD in various new battery systems. Following this introductory section, we then brief the basic structures of LIBs and post-LIBs, and concisely introduce the merits of ALD and MLD in the second part. In the third part, we offer a historic view on the applications of ALD and MLD in various batteries and help readers to secure an integral picture of the two techniques. The fourth part is focused on highlighting some successful case studies that utilized ALD or MLD to tackle the challenging issues in LIBs. In the fifth part, we discuss the successes of ALD and MLD in lithium batteries (i.e., $\mathrm{Li}-\mathrm{S}$ and $\mathrm{Li}-\mathrm{O}_{2}$ batteries), and particularly, we discuss the applications of ALD and MLD for addressing the issues with Li metal anodes. Then, we summarize the achievements of ALD and MLD in designing nanostructured components and the most exciting studies for developing 3D solid-state thin-film batteries in the sixth section. In the end, we conclude this work with some outlook on future studies.

\section{Fundamentals of rechargeable batteries and ALD/MLD}

\section{Basics of LIBs and beyond}

Figure 1 illustrates the general cell structures of LIBs and beyond LIB systems, in which Fig. 1(a) uses liquid electrolytes (LEs), while Fig. 1(b) employs SEs. A liquid cell consists of a pair of electrodes (an anode and a cathode), two current collectors (one for the anode and one for the cathode), a polymer separator, and an LE. In comparison, a solid-state cell has no separators but an SE in place of an LE and a separator. Both the LE and SE are ionically conductive but electrically insulating. The two electrodes have different chemical potentials, dictated by the chemistry that occurs at each [21]. Once the two electrodes are connected with an external device (e.g., a cell phone or an electric vehicle), there is an electron flow formed spontaneously from the more negative (the anode) to the more positive electrode (the cathode). At the same time, ions $\left(\mathrm{M}^{\mathrm{n}+}\right)$ are transported through the LE or SE to maintain the charge balance. After discharge, a larger voltage applied in the opposite direction can cause the battery cells to recharge [21]. Currently, LIBs are widely utilizing oLEs, which consist of an organic solvent and a lithium salt. In this regard, readers may refer to two excellent reviews by $\mathrm{Xu}[22,23]$ to gain more detailed knowledge. SEs can be polymeric (pSEs) [24, $25]$ or inorganic (iSEs) [26, 27]. Recently, there has an evergrowing enthusiasm in iSEs in order to ultimately address the safety issues in LIBs and beyond. The adoption of iSEs can also help the utilization of new electrodes (e.g., sulfur cathodes and lithium anodes in lithium metal batteries). Not limited to $\mathrm{Li}^{+}, \mathrm{M}^{\mathrm{n}+}$ can also be $\mathrm{Na}^{+}, \mathrm{K}^{+}, \mathrm{Mg}^{2+}, \mathrm{Ca}^{2+}, \mathrm{Zn}^{2+}$, or $\mathrm{Al}^{3+}[28,29$, 30 ] in a variety of beyond LIB systems. 


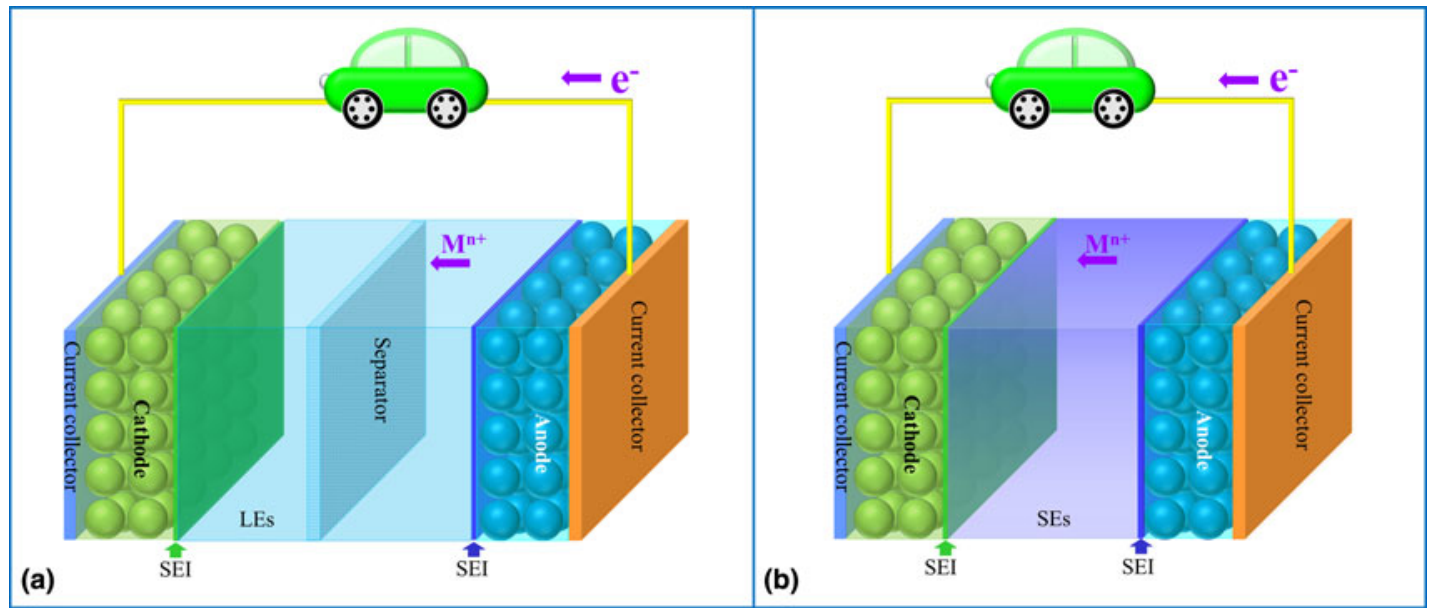

Figure 1: Schematic illustrations of rechargeable batteries for LIBs and beyond using (a) LEs and (b) SEs.

In these battery cells, no matter what electrolytes are used, there are always two interfacial layers between each electrode and the electrolyte, i.e., the so-called solid-electrolyte interphase (SEI) [31, 32] primarily after the first charge-discharge cycle (see Fig. 1). The formation of SEI layers is related to the electrochemical stability of electrodes and electrolytes. A stable SEI layer is critical for battery cells to realize long-term cyclability. Unstable SEI layers continuously consume electrolytes (either LEs or SEs) and the active ions $\left(\mathrm{M}^{\mathrm{n}+}\right)$. This eventually leads to cell failure. The formation of SEI and its nature change with electrodes and electrolytes. Usually, it is hard to form an ideal SEI naturally and it would be preferred to grow an artificial SEI via a chemical process. Traditionally, wet chemistry (e.g., sol-gel methods) have been widely utilized to coat electrode powder materials first. Then, the resultant core-shell structured powders were mixed with conductive additives (e.g., carbon black) and a resin binder to fabricate electrodes for better performance. This strategy has two big drawbacks: (i) the coating layers via wet chemistry are not uniform and very thick, ranging from nanometers to micrometers, and (ii) the coating layers are often electronically insulating and reduce the conductivity of the resultant electrodes. Different from wet chemistry, ALD and MLD are two highly tunable techniques. They can coat nearly any materials uniformly and conformally over any shaped substrates. They can accurately control the coating materials' growth at the atomic/molecular level. They both are to date the only techniques enabling to coat prefabricated electrodes directly. Consequently, ALD and MLD bring new opportunities for us to pursue better batteries.

\section{Fundamentals of ALD and MLD}

\section{Principles of ALD and MLD processes}

ALD and MLD are two sister vapor-phase thin-film techniques, featuring their shared unique capability enabling accurate growth of materials. As a vapor-phase thin-film technique, ALD first emerged in the 1970s for controllably depositing ZnS for flat panel displays [33], while MLD was first reported in 1991 by Yoshimura et al. [34] for controllably growing polymeric films. The two techniques operate with the same procedures to accurately control materials growth. ALD and MLD are complementary in materials. ALD is exclusively for growing inorganic materials at the atomic level, while MLD is specially for growing organic or organic-inorganic hybrid materials at the molecular level [14]. Combining ALD and MLD, one can explore unlimited opportunities for new materials. They both commonly rely on alternative selflimiting surface reactions for materials growth in a layerby-layer mode. To illustrate ALD processes, Fig. 2(a) exemplifies the ALD process of $\mathrm{Al}_{2} \mathrm{O}_{3}$ using trimethylaluminum (TMA, $\left.\mathrm{Al}\left(\mathrm{CH}_{3}\right)_{3}\right)$ and $\mathrm{H}_{2} \mathrm{O}$ as precursors, which can be described as follows [35]:

$$
\begin{gathered}
\left|-\mathrm{OH}+\mathrm{Al}\left(\mathrm{CH}_{3}\right)_{3}(\mathrm{~g}) \rightarrow\right|-\mathrm{O}-\mathrm{Al}\left(\mathrm{CH}_{3}\right)_{2} \\
+\mathrm{CH}_{4}(\mathrm{~g}), \\
\mid-\mathrm{O}-\mathrm{Al}\left(\mathrm{CH}_{3}\right)_{2}+2 \mathrm{H}_{2} \mathrm{O}(\mathrm{g}) \\
\rightarrow \mid-\mathrm{OAl}(\mathrm{OH})_{2}+2 \mathrm{CH}_{4}(\mathrm{~g}),
\end{gathered}
$$

where "|" indicates substrate surfaces, while "(g)" signifies gas phases. The surface chemistry of the $\mathrm{ALD} \mathrm{Al}_{2} \mathrm{O}_{3}$ is based on ligand exchanges between $-\mathrm{OH}$ and $-\mathrm{CH}_{3}$ to arrange atoms accurately in a layer-by-layer mechanism. In addition to the ligand exchange mechanism as illustrated in Eqs. (1a) and (1b), there are other mechanisms for ALD surface chemistry as well, such as dissociation and association [36]. The two gas-solid surface reactions are self-limiting or self-terminating, due to the limited number of surface reactive sites. This nature basically determines the accuracy of ALD in materials growth 


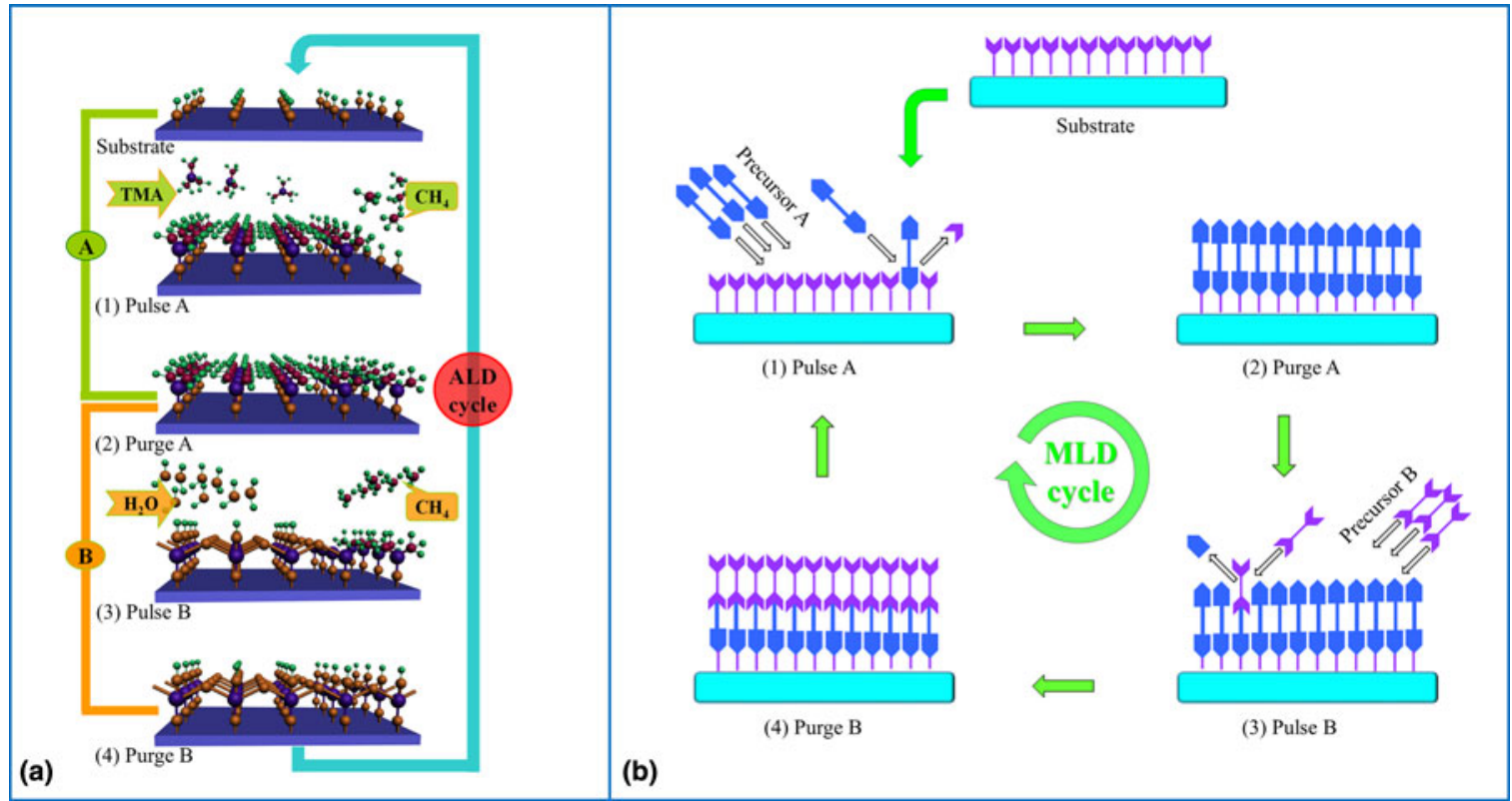

Figure 2: Schematic illustrations of (a) ALD process, which is exemplified by that $\mathrm{ALD} \mathrm{Al}_{2} \mathrm{O}_{3}$ using TMA and water as precursors [15], and (b) MLD process [14]. Reprinted with permission from Ref. [15]. Copyright (2012) John Wiley \& Sons. Reprinted with permission from Ref. [14]. Copyright (2017) The Royal Society of Chemistry.

and its other unique characteristics. The four steps [from 1 to 4 in Fig. 2(a), i.e., Pulse A/Purge A/Pulse B/Purge B] constitute one ALD cycle and they can repeat to build up films for a desired thickness. The growth rate of ALD is described by growth per cycle (GPC), typically $\sim 1 \AA$ cycle [37]. Now ALD has enabled a large variety of materials, including elements [38, 39], oxides [40, 41], sulfides [42, 43, 44], nitrides [39], fluorides [45], and many others [36, 40, 46].

Figure 2(b) displays an MLD process for growing pure polymers using two homobifunctional precursors, consisting of four steps as well, i.e., Pulse A/Purge A/Pulse B/Purge $B$. During the MLD process, a precursor A first reacts with surface reactive groups via a corresponding linking chemistry to add a molecular layer on the substrate surface with new reactive sites [47]. Then, there is a thorough purge A applied to remove the over-dosed precursor A and the byproducts produced. Subsequently, a second precursor B is dosed and reacts with the new reactive sites with the production of another molecular layer. The surface reaction adds another molecular layer and simultaneously recovers the surface back to the initial reactive groups. There is another full purge B performed to remove the over-supplied precursor B and byproducts. The two gassolid surface reactions also are self-limiting. The four steps [from 1 to 4 in Fig. 2(b)] establish one MLD cycle and can be repeated with an increased cycle number for a desirable film thickness. Using adipoyl chloride (AC) and 1, 6-hexanediamine (HD) as precursors [48, 49], e.g., researchers developed an MLD process for growing nylon films linearly and the surface chemistry is described as follows:

$$
\begin{gathered}
\text { I- } \mathrm{NH}_{2}+\mathrm{ClCO}\left(\mathrm{CH}_{2}\right)_{4} \mathrm{COCl}(\mathrm{g}) \\
\rightarrow \text { I- } \mathrm{NHCO}\left(\mathrm{CH}_{2}\right)_{4} \mathrm{COCl}+\mathrm{HCl}(\mathrm{g}) \\
\mid-\mathrm{NHCO}\left(\mathrm{CH}_{2}\right)_{4} \mathrm{COCl}+\mathrm{H}_{2} \mathrm{~N}\left(\mathrm{CH}_{2}\right)_{6} \mathrm{NH}_{2}(\mathrm{~g}) \\
\rightarrow \text { I }-\mathrm{NHCO}\left(\mathrm{CH}_{2}\right)_{4} \mathrm{CO}-\mathrm{NH}\left(\mathrm{CH}_{2}\right)_{6} \mathrm{NH}_{2} \\
+\mathrm{HCl}(\mathrm{g})
\end{gathered}
$$

The AC-HD MLD process realized a GPC of $19 \AA$ /cycle at $62{ }^{\circ} \mathrm{C}$ [49]. The molecular layers of $-\mathrm{CO}\left(\mathrm{CH}_{2}\right)_{4} \mathrm{CO}-$ and $-\mathrm{NH}$ $\left(\mathrm{CH}_{2}\right)_{6} \mathrm{NH}-$ during this MLD nylon process are much larger than the atomic layers of $-\mathrm{Al}-$ and $-\mathrm{O}-$ in the $\mathrm{ALD}-\mathrm{Al}_{2} \mathrm{O}_{3}$. This underlies the higher GPC of the MLD nylon process of AC-HD. Additionally, many more pure polymeric materials via MLD recently have been summarized in the literature [14]. In addition to fabricating pure polymeric films as illustrated in Fig. 2(b), MLD also can deposit organic-inorganic hybrid materials by adopting an ALD precursor and an MLDprecursor, such as TMA and ethylene glycol (EG, $\mathrm{HOCH}_{2} \mathrm{CH}_{2} \mathrm{OH}$, a homobifunctional diol precursor). For more detailed information, one may refer to the recent review article [14], in which recent research progresses of MLD have been comprehensively summarized. To date, MLD has enabled polyazomethines $[50,51,52,53]$, polyureas $[54,55,56,57,58]$, polyamides $[48,49,59,60]$, poly(3,4-ethylenedioxythiophene) [61, 62], polyimide-polyamides [63], polythioureas [64], polyethylene terephthalate [65], and many hybrid materials (such 
as metalcones [66, 67, 68] and metal-organic frameworks (MOFs) [69]). Furthermore, one can combine ALD and MLD for growing an unlimited number of laminated materials, and the resultant laminated materials are highly tunable with controlled layer thickness and layer number of both inorganic and organic components. Thus, ALD and MLD have greatly enriched our skills and choices in new materials.

In ALD and MLD processes, their precursors are critical and should be highly reactive and thermally stable. In addition, it is important for precursors to vaporize with ease. During film deposition, materials growth relies on surface reactions and precursors are required without decomposition occurred during deposition. Otherwise, the growth proceeds in a mode of chemical vapor deposition (CVD). On the other hand, surface properties of substrates, especially types of reactive sites and density of reactive sites, have significant effects on the initial film growth of ALD and MLD processes. To gain a better understanding of an ALD or MLD process, therefore, one should consider all the three parameters, i.e., precursors, temperatures, and substrates.

\section{Characteristics of ALD and MLD}

Both ALD and MLD proceed their growth with self-limiting gas-solid surface reactions. This unique growth mechanism has determined its distinct growth characteristics. The characteristics are exhibited as surface-controlled film growth at the atomic/molecular level, excellent uniformity, unrivaled conformal coating over any shaped structures, high-quality pinholefree films, and low growth temperature (typically less than $300{ }^{\circ} \mathrm{C}$ ). These characteristics well distinguish ALD and MLD from two other vapor-phase thin-film techniques, CVD and physical vapor deposition (PVD), which both are sourcecontrolled processes [70]. ALD enables unparalleled conformal coatings over complex high aspect ratio (HAR, up to $\sim 10^{5}$ [71]) substrates. ALD can even perform at room temperature [72, 73].

Ascribed to the many advantages, ALD and MLD have emerged as an important tool for nanomaterials and nanotechnologies since the very beginning of the 21 st century $[74,75$, 76]. In the past two decades, they both have been offering opportunities to a large variety of applications, ranging from semiconductors to catalysis, clean energies (batteries, supercapacitors, solar cells, and fuel cells), surface engineering, biomedical, and some emerging areas [e.g., two-dimensional (2D) materials and metamaterial]. In this work, we devote to make the first summary outlining the main achievements of ALD and MLD in various battery systems. In pursuing better batteries, the exceptional capabilities of both ALD and MLD have been exhibited in two main aspects: (i) design of nanostructured battery components and (ii) nanoscale interfacial tailoring, as illustrated in Fig. 3. In designing nanostructured

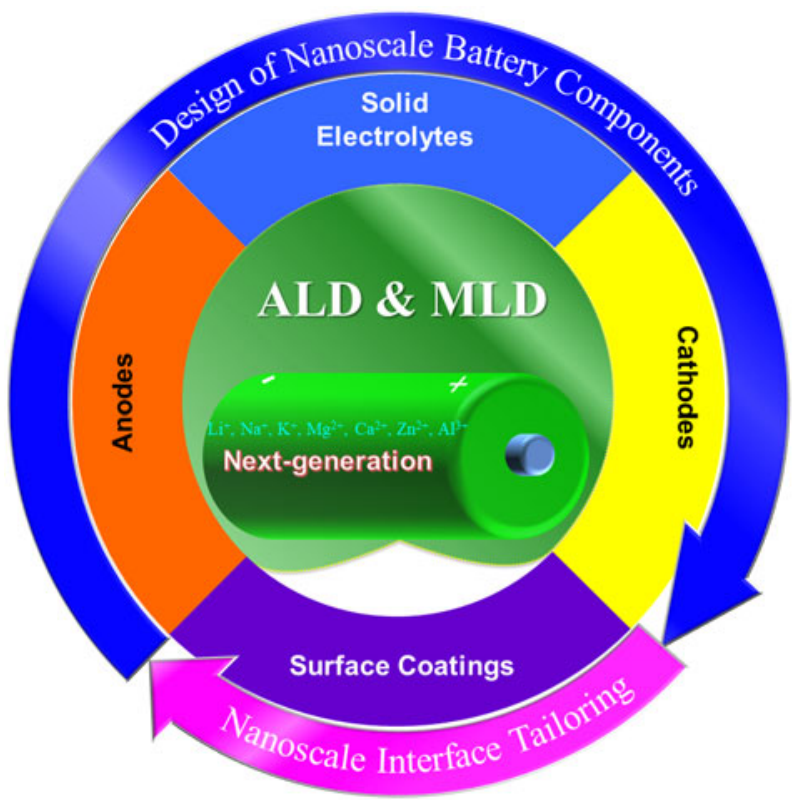

Figure 3: Applications of ALD and MLD in LIBs and beyond.

battery components, ALD has been practiced much more than MLD. To date, there have a large variety of nanostructured anodes and cathodes documented in the literature, while there have more and more nanophase iSEs reported. Integrating all these three components into one system, one can accomplish 2D or even 3D thin-film batteries (also called microbatteries), in which many metals and conductive compounds via ALD are candidates of current collectors. In tailoring interfaces of batteries, ALD and MLD have been used for modifying the surfaces of electrodes or iSE pallets through depositing an ultra-thin coating. ALD and MLD are flexible and they can be used to coat either battery material powders or prefabricated electrodes. In particular, they are to date the only techniques enabling coating prefabricated electrodes directly. Due to these compelling capabilities, ALD and MLD have been attracting more and more research enthusiasm and efforts.

\section{The journey of ALD and MLD for better batteries}

ALD was delivered for producing flat electroluminescent display panels in the 1970s [33]. MLD emerged for growing polyimides in 1991 [34], when LIBs were commercialized by Sony. The first practice of ALD in batteries was for LIBs and appeared in 2000, when $\mathrm{V}_{2} \mathrm{O}_{5}$ nanofilms [77] were electrochemically investigated as a cathode for thin-film LIB batteries in the range of 3.0-3.8 V. Since then, no more work was reported until 2007, when a TiN ALD process [78] was used to coat $\mathrm{Li}_{4} \mathrm{Ti}_{5} \mathrm{O}_{12}$ (LTO) powder in order to improve the 
LTO's conductivity. Electrochemical measurements showed that the electrode made from the ALD-coated LTO powder showed better improved performance. Using ALD for 3D network of hollow $\mathrm{TiO}_{2}$ nanoribbons, in 2009, Kim et al. [79] for the first time demonstrated that ALD is feasible for accurately designing $3 \mathrm{D}$ nanostructured electrode materials with high electrochemical performance. Thereafter, many more 3D nanostructured materials have been fabricated by ALD as electrodes. For instance, there are nanostructured anodes via ALD, such as $\mathrm{TiO}_{2}$ [80, 81], $\mathrm{SnO}_{2}[82,83,84,85], \mathrm{Li}_{4} \mathrm{Ti}_{5} \mathrm{O}_{12}$ [86], MnS [87], $\mathrm{GaS}_{x}[88,89]$, and $\mathrm{AlS}_{x}$ [90]. There also are nanostructured cathodes via ALD, such as $\mathrm{V}_{2} \mathrm{O}_{5}$ [91], $\mathrm{LiFePO}_{4}$ [92], $\mathrm{FePO}_{4}$ [93], and $\mathrm{Cu}_{2} \mathrm{~S}$ [94]. Importantly, in 2009, there also had the first ALD attempt to develop complex lithium-containing compounds as iSEs in a highly tunable mode [95]. iSEs are essential for developing solid-state batteries. Since then, there have been many more iSEs and some prototypes of solid-state thin-film batteries reported, as recently reviewed by Meng [17]. The successes of nanostructured electrodes and iSEs have contributed to a few prototypes of 3D microbatteries $[96,97]$.

In 2010, Jung et al. conducted two significant studies [98, 99], in which they for the first time reported that ALD coatings could be applied not only on electrode powders but also on prefabricated electrodes. In the studies, both the ALD$\mathrm{Al}_{2} \mathrm{O}_{3}$-coated graphite anode and $\mathrm{LiCoO}_{2}$ cathode showed dramatically improved performance with ultra-thin coatings down to less than $1 \mathrm{~nm}$ (e.g., $\sim 0.2 \mathrm{~nm}$ ). These two studies have greatly inspired more studies and significantly advanced ALD as a technique to tailor battery interfaces. Since then, ALD has been employed to modify LIBs, Li-S, Li-O ${ }_{2}, \mathrm{Na}$-based, K-based, and Al-based batteries. So far, the choice of surface coatings via ALD has been greatly enriched, ranging from nitrides [78] and oxides [98, 99, 100, 101, 102] to fluorides [103, 104], sulfides [105], phosphates [106], and oxynitrides [107]. Apparently, ALD has great potentials for developing better LIBs, exhibited in two aspects: (i) design of nanoscale battery components (including anodes, cathodes, and iSEs), leading to solid-state batteries, and (ii) nanoscale interface tailoring, as illustrated in Fig. 3. These exceptional capabilities have been first comprehensively summarized in a review article by Meng et al. [15]. With its successful applications in LIBs, ALD has been receiving more and more attention for developing other post-LIBs, including $\mathrm{Li}-\mathrm{S}$ [108, 109], $\mathrm{Li}-\mathrm{O}_{2}$ [110], sodium-based (SIBs) [111], potassium-based [112], zinc-based [113], and aluminum-based batteries [114].

Along with ALD's wide applications in various battery systems, MLD also has been investigated as a new tool for polymeric and hybrid materials as surface coatings or electrodes in batteries. Leobl et al. [115] made the first attempt on polymeric coatings via MLD, in which an alucone coating was compared to an $\mathrm{ALD} \mathrm{Al}_{2} \mathrm{O}_{3}$ coating for their effects on suppressing
SEI formation and improving sustainable capacities of an LIB carbon anode. Although the MLD alucone did not beat the ALD $\mathrm{Al}_{2} \mathrm{O}_{3}$ in boosting the performance of the carbon anode, some subsequent studies demonstrated that MLD coatings are promising for Si anodes [116], Li metal anodes [117], sodium metal anodes [118], and SIB cathodes [119]. MLD has also been used for synthesizing organic LIB anodes [120]. The journey is just started and, with more enthusiasm and effort invested for ALD and MLD in battery research, there will be more excitements expected.

To facilitate readers in establishing a better picture on the journey of ALD and MLD in rechargeable batteries, we have summarized and highlighted all their milestone studies in Fig. 4. Furthermore, several review articles $[14,15,16,17,18$, $20,121,122,123$ ] are highly recommended, and readers can find more detailed information about the applications of ALD and MLD in batteries.

\section{Advances in LIBs}

It is imperative for LIBs to improve their energy density while reducing their cost. In this regard, both anode and cathode materials play important roles in determining LIB energy density and cost. Traditionally, there are three major types of cathodes for LIBs, i.e., layered LCO, spinel $\mathrm{LiMn}_{2} \mathrm{O}_{4}$ (LMO), and olivine $\mathrm{LiFePO}_{4}$ (LFP). There also have some other variants of these cathodes. Given the expensive cost and toxic nature of $\mathrm{Co}$, for instance, researchers have explored some derivatives of the layered LCO, such as $\mathrm{LiNi}_{x} \mathrm{Mn}_{y} \mathrm{Co}_{z} \mathrm{O}_{2}$ (NMC, $x+y+$ $z=1), \quad \mathrm{LiNi}_{0.80} \mathrm{Co}_{0.15} \mathrm{Al}_{0.05} \mathrm{O}_{2} \quad$ (NCA), Li-Mn-rich oxide $\mathrm{Li}_{1.2}[\mathrm{MnNiCo}]_{0.8} \mathrm{O}_{2}$, and others $[124,125]$. On the side of the anodes, there have many candidate materials. Among them, $\mathrm{Si}$ is the most promising anode material, featuring its extremely high capacity and natural abundance. However, all these electrode materials have technical issues in their applications. To this end, ALD and MLD have been being applied as important measures for addressing their issues in the past decade.

\section{Si anodes}

$\mathrm{Si}$ as an anode is particularly attractive and can enable a very high gravimetric energy density of $3579 \mathrm{mAh} / \mathrm{g}$ at room temperature, which is about 10 times higher than that of commercial graphite anodes. In addition, $\mathrm{Si}$ has a relatively low discharging potential of $\sim 0.2 \mathrm{~V}$ versus $\mathrm{Li} / \mathrm{Li}^{+}$. Furthermore, $\mathrm{Si}$ is cost-effective, abundant on the earth, and environmentally benign. All these jointly determine that $\mathrm{Si}$ is an ideal anode for LIBs. However, Si suffers from a huge volume change of $\sim 300 \%$ during charge-discharge processes of LIBs at room temperature [126, 127]. This issue causes a series of other 

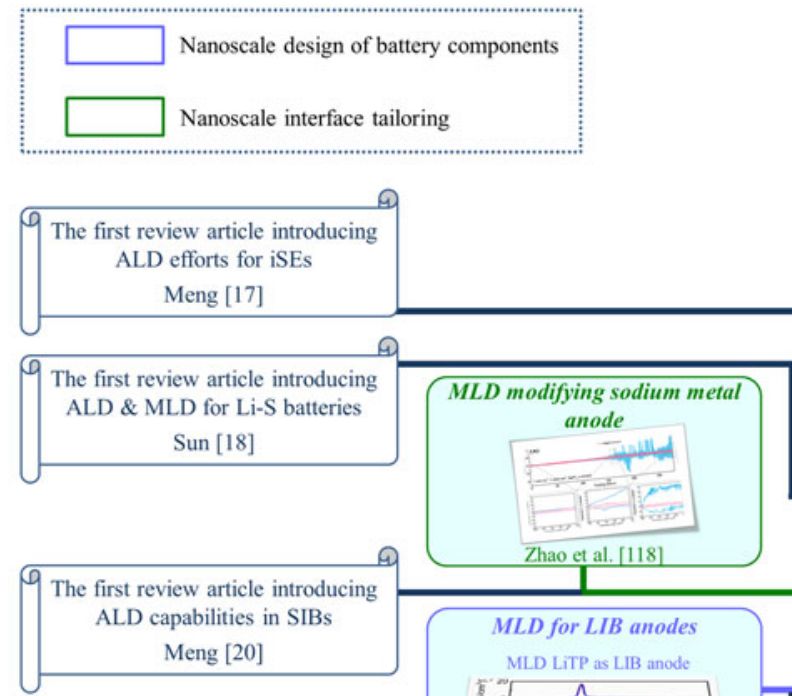

,

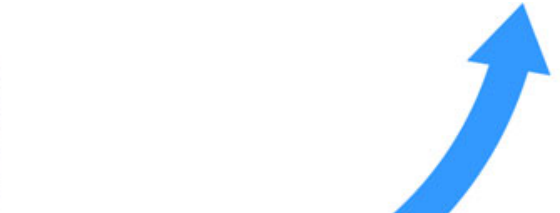

9 The first review article introducing MLD for surface coating in LIBs Ban and George [121]

\section{.}
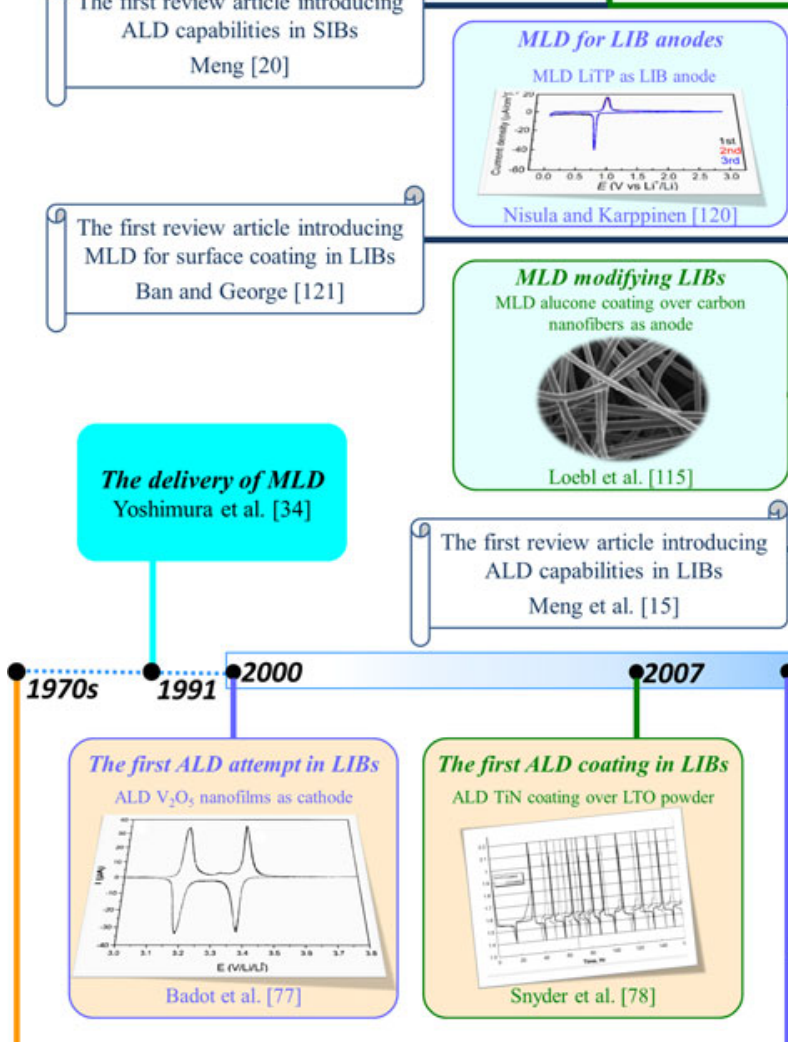

The delivery of $A L D$

Suntola and Antson [33]
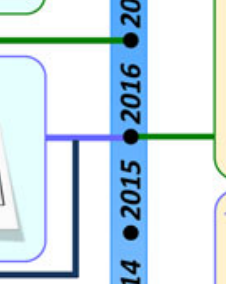

Zn-based batteries ALD TiO, co over $\mathrm{Zn}$ metal

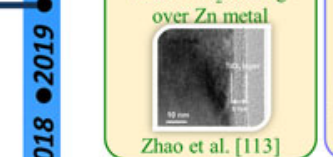
Aluminum-ion Batteries

$3 D$ solid-state ALD of $\mathrm{ZnO}$ as cathode microbatter
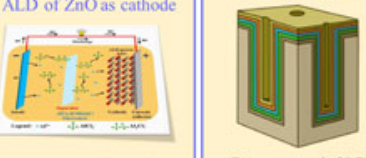

Pal et al. [114] Pearse et al. [97]
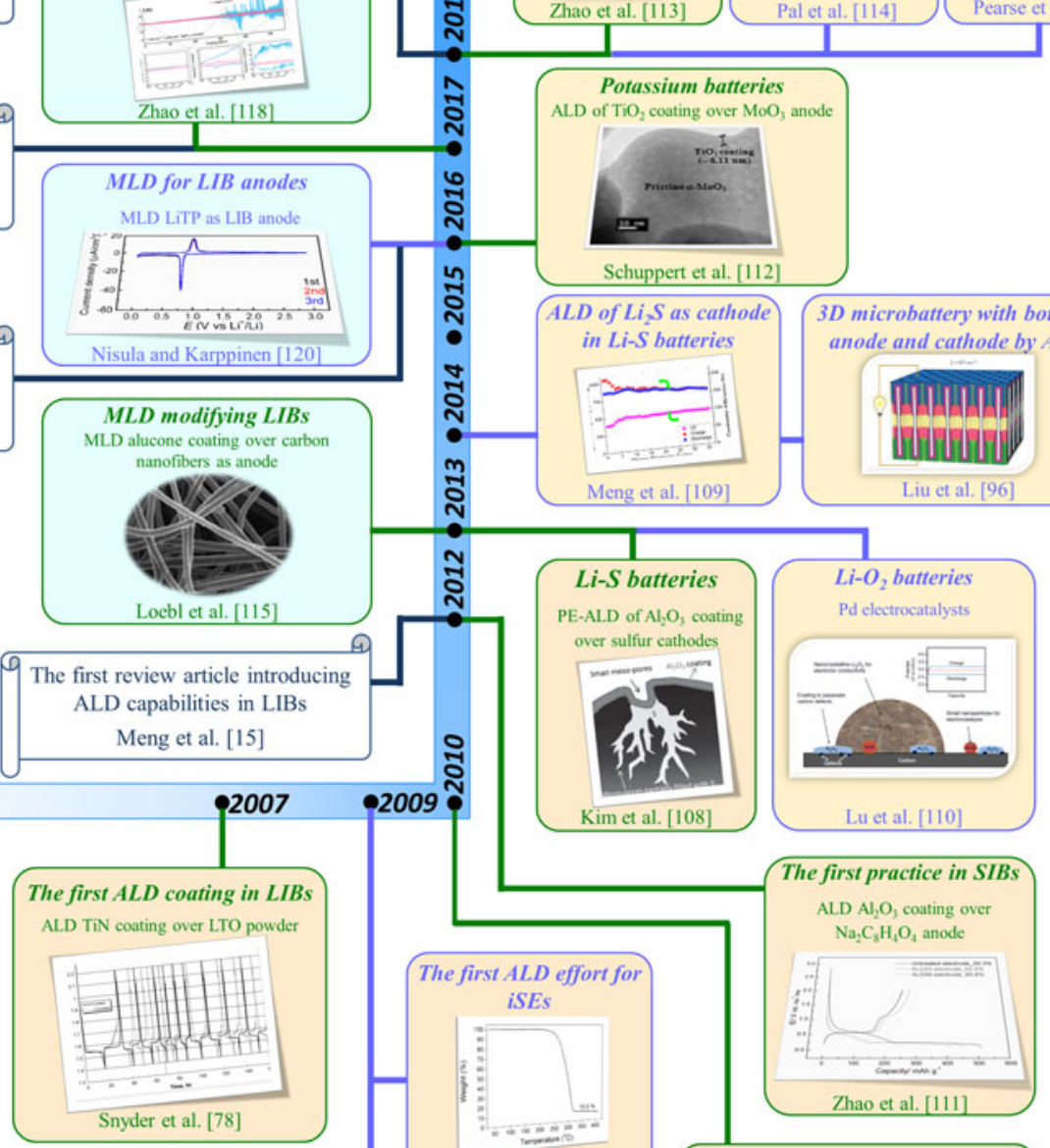
ALD capabilities in LIBs Meng et al. [15] 

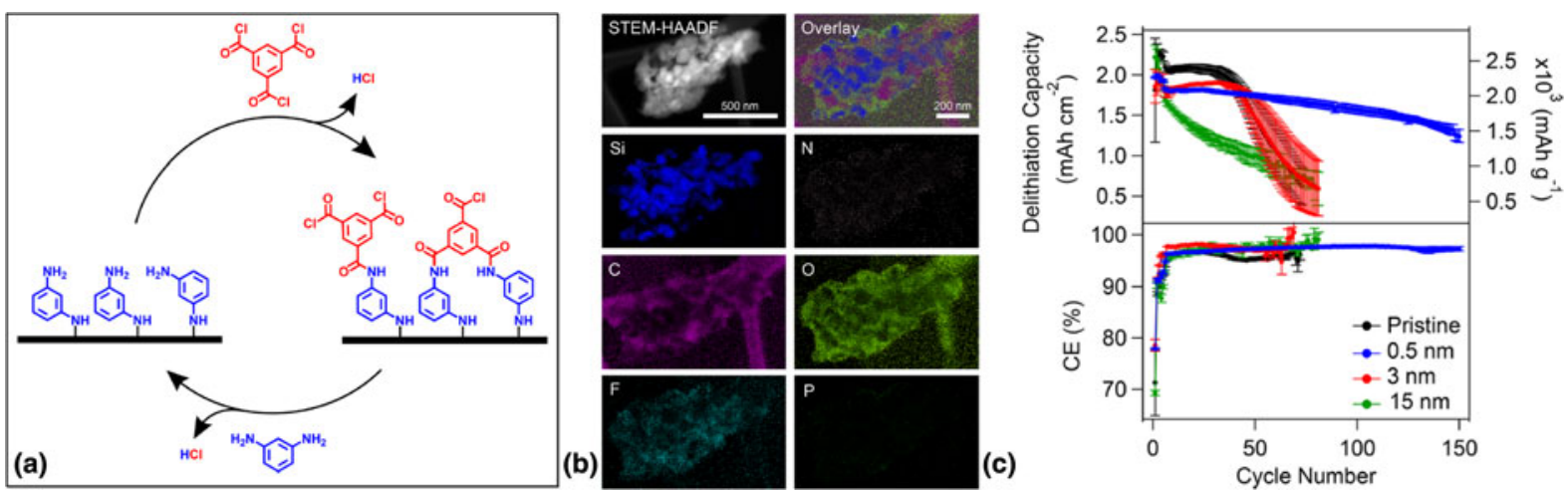

Figure 5: Effects of an MLD polyamide coating on Si anodes [128]. (a) Reaction mechanism of the MLD aromatic polyamide thin film using the precursors of trimesoyl chloride and $m$-phenylenediamine. (b) STEM-HAADF-EDS of Si nanoparticles extracted from an Si composite electrode initially coated with 15-nm-thick polyamide after electrochemical cycling. The Si particles show a distinct morphology change. Despite this morphology change, the nitrogen signal representative of the polyamide coating is still present in the area of the Si particles. (c) Galvanostatic discharge and charge cycling of pristine Si composite electrodes compared to those coated with $0.5-, 3-$, and $15-\mathrm{nm}$ polyamide coating. The first five cycles were run at a C/25 rate, and the following cycles were run at a C/10 rate. The 0.5 -nm coating was deposited with long precursor exposure times, and the other two coatings were deposited with short precursor exposure times. Reprinted with permission from Ref. [128]. Copyright (2019) American Chemical Society.

problems, such as electrochemical pulverization, continuous SEI formation, consumption of oLEs, and continuously increased cell impedance. These issues lead to electrochemical degradation and ultimately cell failure. To overcome this challenge, the surface coating has proved being effective to maintain mechanical integration of $\mathrm{Si}$ anodes, eliminate SEI formation, and therefore boost their electrochemical performance. Many inorganic coatings via ALD have been studied for improving Si anodes [16], but they generally have little elasticity to accommodate the large volume expansion and contraction of Si. Thus, ALD-deposited inorganic coatings have some limitation to sustain a long-term cyclability of Si anodes. In contrast, MLD organic coatings are potentially more attractive. In this regard, Piper et al. [116] first investigated the effects of an MLD coating of alucone (denoted as AlGL) on Si anodes. In the work, they revealed that a 5-nm-thick MLD AlGL coating could dramatically improve the coated Si anodes' performance. Piper et al. [116] explained that the AlGL coating helped preserve the electrode network, accounting for a $17.5 \%$ volume increase after 20 electrochemical cycles for the coated electrode, while a $50 \%$ volume increase for the bare electrode. Thus, the AlGL coating has proved to be robust and resilient enough to accommodate the extreme volumetric changes of the Si nanocomposite electrodes. In a recent work, Wallas et al. [128] deposited a layer of polyamide coating [Fig. 5(a)] over $\mathrm{Si}$ anodes using a spatial MLD system at $150^{\circ} \mathrm{C}$. Elemental mapping [Fig. 5(b)] of Si nanoparticles extracted from a 15-nm coated electrode after cycling showed that the nitrogen signal indicated the presence of the MLD coating over the Si nanoparticles. The mapping was conducted using STEM-HAADF-EDS (STEM: scanning transmission electron microscopy, HAADF: high-angle annular dark-field imaging, and EDS: energydispersive X-ray spectroscopy). The other elements were from
Si particles and the formed SEI. The Si particles underwent a morphology change from spherical particles to irregularly shaped particles. The STEM results revealed that the MLD polyamide coating might maintain intimate contact with the Si particles during electrochemical cycling. Electrochemical measurements [Fig. 5(c)] disclosed that the $0.5-\mathrm{nm}$ polyamide coating evidently improved the coated Si electrode's sustainable capacity, cyclability, and Coulombic efficiency (CE). On the contrary, the 3- and 15-nm-thick polyamide coatings did not perform well. Wallas et al. [128] pointed out that the $0.5-\mathrm{nm}$ coating was deposited with a 6-s exposure time, while the 3and 6-nm coatings were deposited with a 0.6-s exposure. The shorter exposure might have led to less conformal coatings, compared to the ones deposited using the longer exposure. Wallas et al. [128] emphasized that this polyamide coating was an all-organic polymer, five times thinner than that of the MLD AlGL, and deposited using a spatial reactor. In addition to these studies using MLD organic coatings, readers may refer to our recent review article [16] for the effects of ALD coatings on $\mathrm{Si}$ anodes.

\section{Spinel $\mathrm{LiNi}_{0.5} \mathrm{Mn}_{1.5} \mathrm{O}_{4}$ (LNMO) cathode}

Spinel LMO is the most widely used cathode material in both EVs and PHEVs [129]. However, it has low-energy density and suffers from stability issues at high temperature. To this end, $\mathrm{Ni}$ doping has proved to be effective and the resultant $\mathrm{LiNi}_{0.5} \mathrm{Mn}_{1.5} \mathrm{O}_{4}$ (LNMO) features high operating voltage $\left(\sim 4.7 \mathrm{~V}\right.$ versus $\left.\mathrm{Li} / \mathrm{Li}^{+}\right)$, high rate capability, and low cost. However, LNMO has been harassed by electrolyte decomposition and metal dissolution. To address these issues, many efforts have been invested using both ALD and MLD coatings, including oxides [130], fluorides [104, 131], and polymeric 

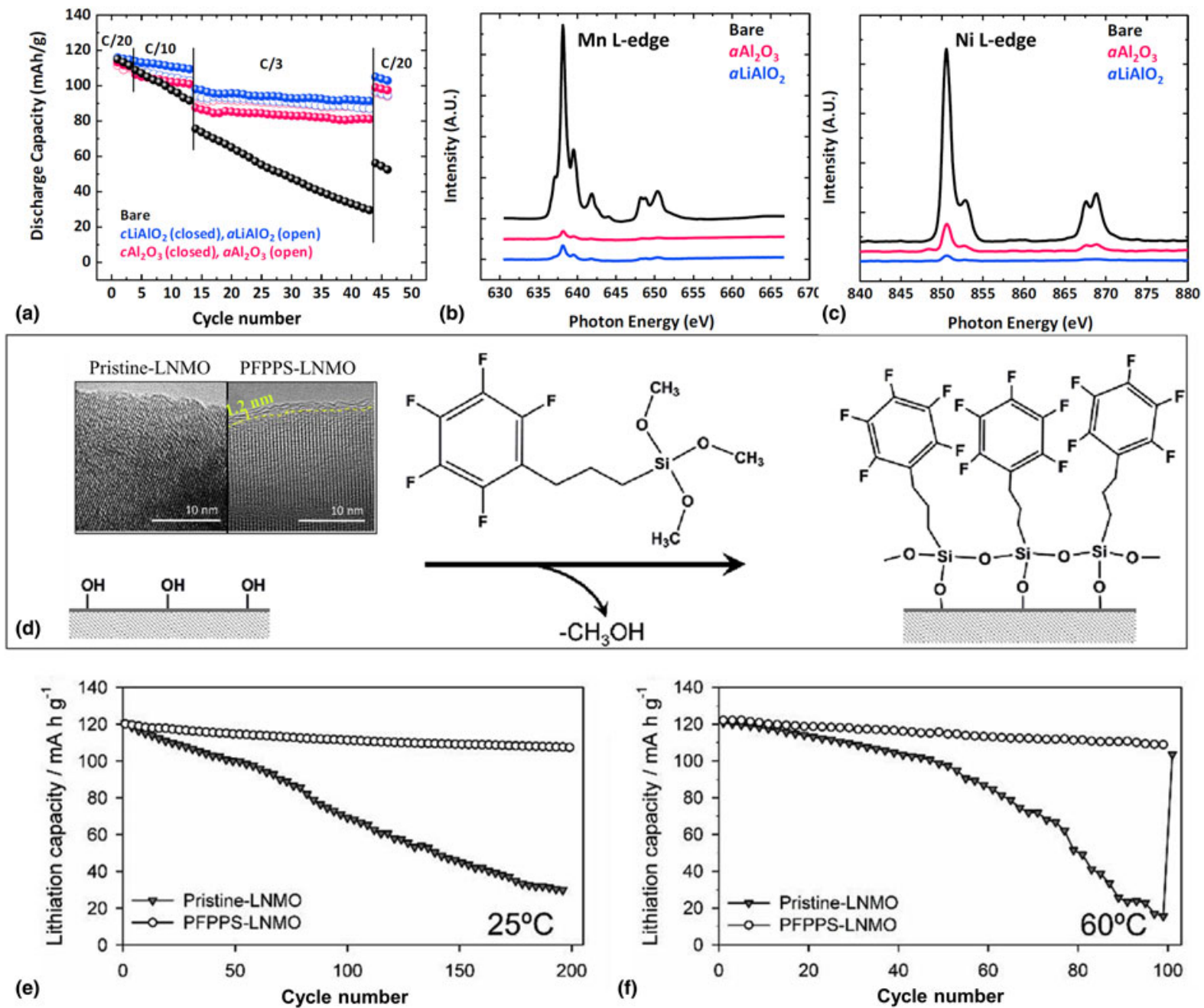

Figure 6: Effects of ALD and MLD coatings on $\mathrm{LiNi}_{0.5} \mathrm{Mn}_{1.5} \mathrm{O}_{4}$ cathodes. (a) Discharge capacities of LiNi ${ }_{0.5} \mathrm{Mn}_{1.5} \mathrm{O}_{4} / \mathrm{graphite}$ cells, i.e., Bare (black closed), cLiAlO (blue closed), $a \mathrm{LiAlO}_{2}$ (blue open), $\mathrm{CAl}_{2} \mathrm{O}_{3}$ (red closed), and $a \mathrm{Al}_{2} \mathrm{O}_{3}$ (red open) at RT (based on the mass of $\mathrm{LiNi}_{0.5} \mathrm{Mn}_{1.5} \mathrm{O}_{4}$ ) [130]. (b) $\mathrm{Mn}$ and (c) $\mathrm{Ni} \mathrm{L}$-edge X-ray absorption spectra of Bare (black), $a$ LiAlO 2 (blue), and $a \mathrm{Al}_{2} \mathrm{O}_{3}$ (red) graphite surface [130]. Reprinted with permission from Ref. [130]. Copyright (2014) American Chemical Society. (d) Schematic illustration of self-assembly procedure for (pentafluorophenylpropyl)trimethoxysilane (PEPPS) on LiNi ${ }_{0.5} \mathrm{Mn}_{1.5} \mathrm{O}_{4}$ surface. Capacity retention of $\mathrm{LiNi}_{0.5} \mathrm{Mn}_{1.5} \mathrm{O}_{4}$ cathodes tested at (e) 25 and (f) $60{ }^{\circ} \mathrm{C}$ at $0.5 \mathrm{C}$. In (f), the lithiation capacity observed at a slower rate $(0.05 \mathrm{C}$ ) at the $101 \mathrm{st}$ cycle is present [132]. Reprinted with permission from Ref. [132]. Copyright (2018) Elsevier.

materials [132]. Among these studies, lithium-containing coatings and polymeric materials are particularly interesting. In these regards, we recently conducted a comparative study using two ALD coatings, $\mathrm{Al}_{2} \mathrm{O}_{3}$ and $\mathrm{LiAlO}_{2}$ [130]. The coatings were applied on either graphite anodes or LNMO cathodes for two ALD cycles. Then, coupling 2-cycle coated/uncoated LNMO cathodes with 2-cycle coated/uncoated graphite anodes, we received and investigated five combinations of LNMO/graphite cells: (i) uncoated cathode/uncoated anode (Bare), (ii) $\mathrm{LiAlO}_{2}$-coated cathode/uncoated anode $\left(c \mathrm{LiAlO}_{2}\right)$, (iii) $\mathrm{Al}_{2} \mathrm{O}_{3}$-coated cathode/uncoated anode $\left(c \mathrm{Al}_{2} \mathrm{O}_{3}\right)$, (iv) uncoated cathode $/ \mathrm{LiAlO}_{2}$-coated anode $\left(a \mathrm{LiAlO}_{2}\right)$, and (v) uncoated cathode/ $/ \mathrm{Al}_{2} \mathrm{O}_{3}$-coated anode $\left(a \mathrm{Al}_{2} \mathrm{O}_{3}\right)$. Electrochemical measurements revealed that, at different rates, the discharge capacity of the Bare cell faded quickly with cycle number, while all the other cells with a coated electrode exhibited an evident improvement in retention in 50 cycles [Fig. 6(a)]. Among all the cells, the $c \mathrm{LiAlO}_{2}$ cell exhibited the best performance, followed by $a \mathrm{LiAlO}_{2}, a \mathrm{Al}_{2} \mathrm{O}_{3}$, and $c \mathrm{Al}_{2} \mathrm{O}_{3}$ at $\mathrm{C} / 3$. This work disclosed that lithium-containing coatings may be a new solution to improve LIB performance. Compared to $\mathrm{Al}_{2} \mathrm{O}_{3}, \mathrm{LiAlO}_{2}$ has a higher ionic conductivity of $5.6 \times 10^{-8} \mathrm{~S} / \mathrm{cm}$ at room temperature. Furthermore, we also revealed that, at any rate, the cells with a coated graphite electrode showed much better cyclability than that of the Bare cell. To this end, we measured $\mathrm{Mn}$ and $\mathrm{Ni} \mathrm{L}$ edges of graphite anodes using synchrotron-based X-ray absorption spectroscopy (XAS) [Figs. 6(b) and 6(c)], showing that both $\mathrm{Mn}$ and $\mathrm{Ni}$ had dissolved from the cathode and migrated to the graphite anodes where they deposited. In addition, the XAS data confirmed that both $\mathrm{Mn}$ and Ni were 
in their +2 oxidation state on the surface of graphite. In comparison, the XAS data showed that the coated graphite anodes had much weaker signals of metal ions, implying the coatings had stabilized the anode surface.

In addition to the ALD coatings, a recent study investigated the effects of an MLD polymer coating, (pentafluorophenylpropyl)trimethoxysilane (PFPPS) [Fig. 6(d)] on LNMO cathodes [132]. The deposited PEPPS layer on the LNMO powders was verified through surface analyses using X-ray photoelectron spectroscopy (XPS) and transmission electron microscopy (TEM) [inset of Fig. 6(d)]. TEM revealed a 1.2-nm-thick monolayer PFPPS. The coated LNMO powders were further fabricated into electrodes, i.e., PFPPS-LNMO. Electrochemical testing demonstrated that, in the range of 3.5-4.9 V, the Li/PFPPS-LNMO cell outperformed the $\mathrm{Li} /$ pristine-LNMO cell, in terms of CE and capacity retention at 25 [Fig. 6(e)] and $60{ }^{\circ} \mathrm{C}$ [Fig. 6(f)]. The elevated temperature of $60^{\circ} \mathrm{C}$ has made the effects of the MLD PFPPS coating more prominent [Fig. $6(\mathrm{f})$ ]. At $60^{\circ} \mathrm{C}$, the pristine-LNMO electrode lost $\sim 88 \%$ of its initial capacity within 100 cycles, while the PFPPS-LNMO remained its initial capacity in the majority. Chae et al. [132] explored the underlying mechanism for cell failure and performed one more charge-discharge at 101st cycle using a much smaller rate, 0.05 C. It was found that the Li/pristine-LNMO cell could almost regain its initial capacity [see Fig. 6(f)]. This strongly suggested that the cell polarization was the failure mechanism, rather than loss of active material itself. Chae et al. [132] believed that, in other words, SEI formation (due to electrolyte decomposition) should be the main reason for the pristine cell failure. In contrast, the PFPPS coating has significantly inhibited the electrolyte decomposition and thereby greatly mitigated the SEI formation. Chae et al. [132] further conducted XPS analyses on cycled pristine and PFPPS-coated LNMO electrodes and confirmed that there had significant SEI formation on the pristine electrode surface but moderate SEI formation on the PFPPS-coated electrode. Thus, the MLD PFPPS coating is effective in suppressing electrolyte oxidation and thereby improving the cell performance remarkably.

\section{Layered Li- and Mn-rich cathodes}

Li- and Mn-rich layered oxides (LMROs), $x \mathrm{Li}_{2} \mathrm{MnO}_{3} \cdot(1-x)$ $\mathrm{LiMO}_{2}(\mathrm{M}=\mathrm{Ni}, \mathrm{Mn}, \mathrm{Co})$, are promising cathode materials for LIBs because of their high specific capacity that can exceed $250 \mathrm{mAh} / \mathrm{g}$ [133]. However, LMROs suffer from several challenges in applications [133]: (i) large irreversible capacity in the 1st cycle, (ii) gradual capacity fading and average discharge voltage decay during prolonged cycling, and (iii) poor rate capability. Several strategies have been investigated to address these issues, such as element-doping and surface coating. In recent years, ALD has been regarded as an important tool to accurately modify LMORs with conformal coatings. In one of our previous efforts, we have investigated the effects of ALD $\mathrm{Al}_{2} \mathrm{O}_{3}$ coatings on $\mathrm{Li}_{1.2} \mathrm{Ni}_{0.2} \mathrm{Mn}_{0.6} \mathrm{O}_{2}$ cathodes [134]. We coated the $\mathrm{Li}_{1.2} \mathrm{Ni}_{0.2} \mathrm{Mn}_{0.6} \mathrm{O}_{2}$ powders with a layer of $\sim 1$-nm thick $\mathrm{Al}_{2} \mathrm{O}_{3}$ via $\mathrm{ALD}$ and then fabricated them into electrodes. The resultant coated $\mathrm{Li}_{1.2} \mathrm{Ni}_{0.2} \mathrm{Mn}_{0.6} \mathrm{O}_{2}$ electrodes were comparatively investigated with the pristine electrodes. Results showed that the coated electrodes could help maintain higher energy and CEs than those of the pristine electrodes, ascribed to the stabilization of the $\mathrm{Li}_{1.2} \mathrm{Ni}_{0.2} \mathrm{Mn}_{0.6} \mathrm{O}_{2}$ material's surfaces. However, the $\mathrm{ALD} \mathrm{Al}_{2} \mathrm{O}_{3}$ coating could not resolve the voltage fade of the electrodes. In another work, we made a comparative study on different coating materials from different coating techniques [135], including $\mathrm{Al}_{2} \mathrm{O}_{3}, \mathrm{TiO}_{2}, \mathrm{ZrO}_{2}, \mathrm{AlPO}_{4}$, $\mathrm{LiAlO}_{x}$, and LiPON. The effects of the six surface coatings on the $0.5 \mathrm{Li}_{2} \mathrm{MnO}_{3} \cdot 0.5 \mathrm{LiNi}_{0.375} \mathrm{Mn}_{0.375} \mathrm{Co}_{0.25} \mathrm{O}_{2}$ electrodes were studied. As an LMRO cathode, $0.5 \mathrm{Li}_{2} \mathrm{MnO}_{3} \cdot 0.5 \mathrm{LiNi}_{0.375}$ $\mathrm{Mn}_{0.375} \mathrm{Co}_{0.25} \mathrm{O}_{2}$ is very attractive due to its high electrochemical capacity of over $280 \mathrm{mAh} / \mathrm{g}$ [136]. Our study revealed that both the ALD-deposited $\mathrm{LiAlO}_{x}$ (six super cycles, $\sim 1 \mathrm{~nm}$ ) and a sputtered LiPON film outperformed all the other coatings and showed a comparable effect on sustaining high capacity. The ALD $\mathrm{LiAlO}_{x}$ and the sputtered LiPON coating are two iSEs and have better ionic conductivity than that of the other metal oxides $\left(\mathrm{Al}_{2} \mathrm{O}_{3}, \mathrm{ZrO}_{2}, \mathrm{TiO}_{2}\right.$, and $\left.\mathrm{AlPO}_{4}\right)$ in our study. It might imply that lithium-ion conductors are more beneficial than oxides to improve cathodes' performance, owing to their higher ionic conductivity. This is consistent to our results from the study of LNMO cathodes as discussed above [130].

More recently, Gao et al. [137] conducted an interesting study on an $\mathrm{Li}_{1.13} \mathrm{Mn}_{0.54} \mathrm{Ni}_{0.13} \mathrm{Co}_{0.14} \mathrm{O}_{2}$ cathode material using ALD. In the work, the researchers performed an ALD process of iron oxide $\left(\mathrm{FeO}_{x}\right)$ on the cathode powders and annealed the coated powders. The powders were coated in a fluidized-bed ALD with different ALD cycles at $450^{\circ} \mathrm{C}$, i.e., 0, 20, 40, and 100 cycles, and named as UC, $20 \mathrm{Fe}, 40 \mathrm{Fe}$, and $100 \mathrm{Fe}$, respectively. Furthermore, these coated and uncoated powders were annealed at $700{ }^{\circ} \mathrm{C}$ in air for $24 \mathrm{~h}$ and cooled naturally, and named as $\mathrm{AUC}, \mathrm{A} 20 \mathrm{Fe}, \mathrm{A} 40 \mathrm{Fe}$, and $\mathrm{A} 100 \mathrm{Fe}$, respectively. Using XPS and TEM, Gao et al. [137] analyzed the annealing effects. They found that the annealing led to the diffusion of Fe into the structure of the $\mathrm{Li}_{1.13} \mathrm{Mn}_{0.54} \mathrm{Ni}_{0.13} \mathrm{Co}_{0.14} \mathrm{O}_{2}$ material. TEM analyzed the annealed sample locally [Fig. 7(a)]. The fast Fourier transform (FFT) pattern [Figs. (7b)-(7d)] generated from Fig. 7(a) suggested that the surface spinel coating was formed and completely epitaxially grown on the inner lattice of the $\mathrm{Li}_{1.13} \mathrm{Mn}_{0.54} \mathrm{Ni}_{0.13} \mathrm{Co}_{0.14} \mathrm{O}_{2}$ material with the epitaxial growth relationships as follows: $[110]_{\mathrm{R}} / /[110]_{\text {spinel }},(300)_{\mathrm{R}} / /(\overline{1} 11)_{\mathrm{s}}$, $(1 \overline{11})_{\mathrm{R}} / /(2 \overline{2} 2)_{\mathrm{s}}$, where $\mathrm{R}$ and $\mathrm{s}$ denote $\mathrm{R}-3 \mathrm{~m}$ layered and cubic spinel structures, respectively. In addition, they noticed that 

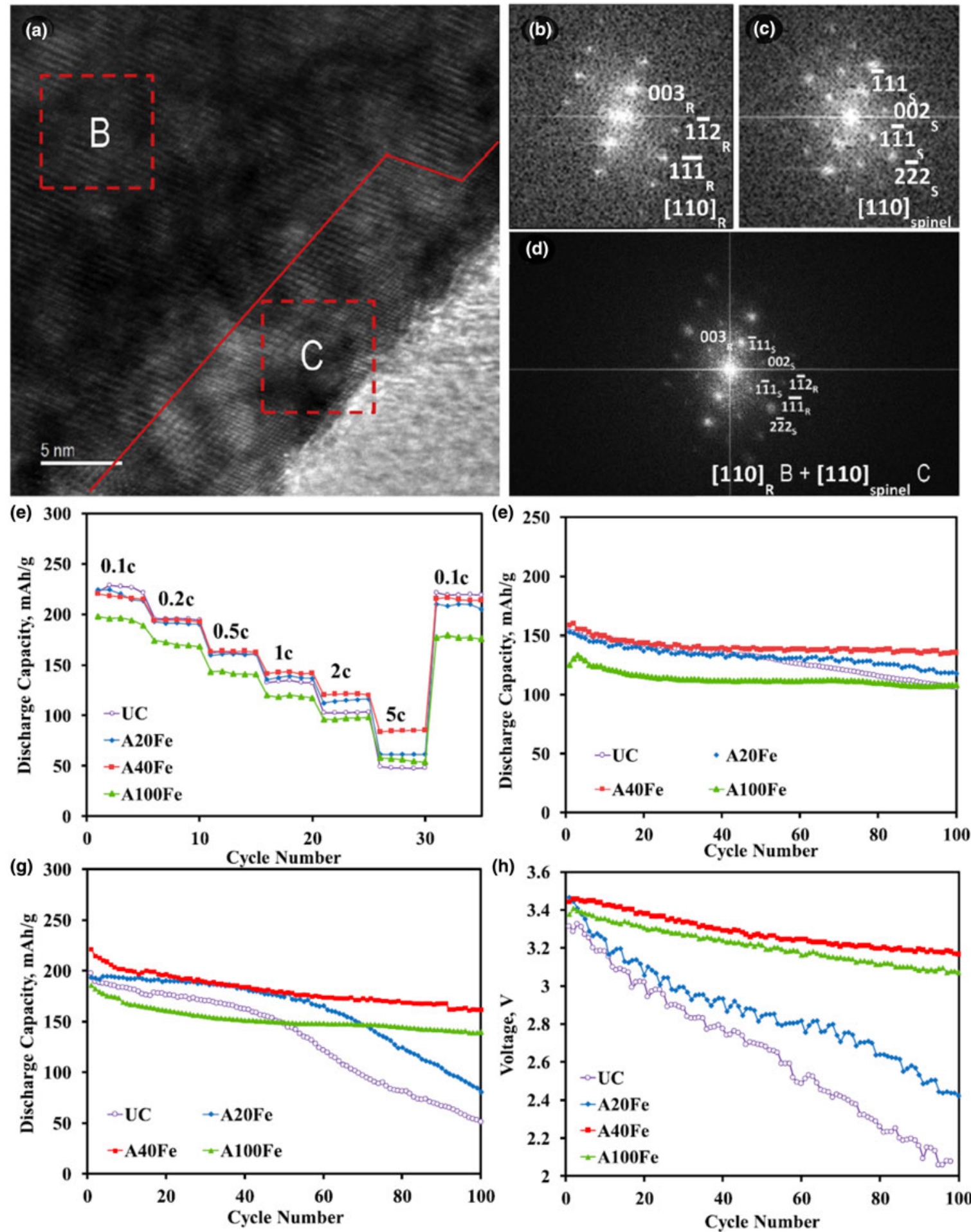

Figure 7: Effects of $\mathrm{ALD} \mathrm{FeO}$ coating on the $\mathrm{Li}_{1.13} \mathrm{Mn}_{0.54} \mathrm{Ni}_{0.13} \mathrm{Co}_{0.14} \mathrm{O}_{2}$ cathode [137]. (a) High-resolution TEM image of an A150Fe particle and (b-d) fast Fourier transform patterns from the regions B and C denoted in (a). (e) Rate capability of UC, A20Fe, A40Fe, and A100Fe at room temperature. Cyclability of different electrodes at (f) room temperature and $(\mathrm{g}) 55^{\circ} \mathrm{C}$ at $1 \mathrm{C}$. (h) Voltage decay of $\mathrm{UC}, \mathrm{A} 20 \mathrm{Fe}, \mathrm{A} 40 \mathrm{Fe}$, and $\mathrm{A} 100 \mathrm{Fe}$ at $1 \mathrm{C}$ at room temperature. Reprinted with permission from Ref. [137]. Copyright (2019) Elsevier.

the diffraction spots of the (003) and (111) planes of the layered structure were completely overlapped with the ( $(\overline{1} 11)$ and $(2 \overline{2} 2)$ of the spinel phase, implying that the growth of the surface coating on the inner lattice of the $\mathrm{Li}_{1.13} \mathrm{Mn}_{0.54} \mathrm{Ni}_{0.13} \mathrm{Co}_{0.14} \mathrm{O}_{2}$ material is almost free from lattice strain. Using the uncoated, coated, and annealed powders to fabricate electrodes, Gao et al. 
[137] investigated their electrochemical performance. First, they revealed that, among electrodes made from uncoated and $\mathrm{FeO}_{x}$-coated powders, $40 \mathrm{Fe}$ enabled the best performance, in terms of rate capability and long-term cyclability at $1 \mathrm{C}$ at both room temperature and $55^{\circ} \mathrm{C}$. More encouragingly, Gao et al. [137] disclosed that the electrodes made from the annealed coated powders performed better than the electrodes made from uncoated and annealed uncoated powders. In particular, A40Fe exhibited the best performance, in terms of rate capability [Fig. 7(e)] and long-term cyclability at room temperature [Fig. $7(\mathrm{f})]$ and $55^{\circ} \mathrm{C}$ [Fig. $\left.7(\mathrm{~g})\right]$ at 1C. A40Fe could deliver an initial capacity of $158 \mathrm{mAh} / \mathrm{g}$ with a capacity retention of $\sim 85 \%$ after 100 charge-discharge cycles at room temperature [Fig. $7(\mathrm{f})]$ and $221 \mathrm{mAh} / \mathrm{g}$ with $\sim 73 \%$ at $55^{\circ} \mathrm{C}$ [Fig. 7(g)]. In contrast, UC enabled a comparable initial capacity but had a much less retention at room temperature. At $55^{\circ}$ $\mathrm{C}$, the situation was even worsened, and UC could only retain $26 \%$ of the initial capacity after 100 cycles. Furthermore, Gao et al. [137] disclosed that the A40Fe electrode exhibited an average voltage dropping rate of $3.6 \mathrm{mV} /$ cycle, while the average voltage dropping rate of UC was $13 \mathrm{mV} /$ cycle [Fig. 7(h)]. In the study, the researchers unveiled that the enhancement of $\mathrm{Li}^{+}$transport and cyclic stability was stemmed from a stable Fe-doped spinel phase on the surface of the cathode particles after ALD coating followed by an annealing. This modification has limited impedance growth and suppressed electrolyte degradation and metal dissolution.

\section{Layered Ni-rich cathodes}

NMC is an important class of variants to LCO and can have different compositions, such as $\mathrm{LiNi}_{1 / 3} \mathrm{Mn}_{1 / 3} \mathrm{Co}_{1 / 3} \mathrm{O}_{2}$ ( $\mathrm{NMC111}$ ), $\mathrm{LiNi}_{0.4} \mathrm{Mn}_{0.4} \mathrm{Co}_{0.2} \mathrm{O}_{2}$ (NMC442), $\mathrm{LiNi}_{0.5} \mathrm{Mn}_{0.3} \mathrm{Co}_{0.2} \mathrm{O}_{2}$ (NMC532), $\mathrm{LiNi}_{0.6} \mathrm{Mn}_{0.2} \mathrm{Co}_{0.2} \mathrm{O}_{2}$ (NMC622), and $\mathrm{LiNi}_{0.8} \mathrm{Mn}_{0.1} \mathrm{Co}_{0.1} \mathrm{O}_{2}$ (NMC811). Among these cathode materials, Ni-rich NMC (the friction of $\mathrm{Ni} \geq 0.5$ ) materials are very promising. With the increased fraction of $\mathrm{Ni}$, the discharge capacity can be increased, while the cost is reduced. However, the increased $\mathrm{Ni}$ fraction is prone to cause more issues, such as structural instability, Li/Ni mixing, oxygen release, and intergranular and intragranular crack formation. In addressing these issues, the surface coating has been being practiced as an important measure and ALD has been an important tool to modify NMC cathodes at the atomic scale accurately.

Metal oxides are the most studied coating materials to date for modifying $\mathrm{NMC}$ cathodes, such as $\mathrm{Al}_{2} \mathrm{O}_{3}$ [138], $\mathrm{ZrO}_{2}$ [139], and $\mathrm{TiO}_{2}$ [102]. More recently, there has an increasing interest in lithium-ion conductors as coatings, including $\mathrm{Li}_{3} \mathrm{PO}_{4}[140$, 141], $\mathrm{LiTaO}_{3}$ [142], and $\mathrm{LiAlF}_{4}$ [103]. Among these studies, our recent work is very representative to demonstrate the beneficial effects of metal oxides on NMC622 [102]. Ascribed to its distinct capability, in our work ALD was applied to coat prefabricated NMC622 electrodes directly with varied cycles $(20,40$, 60 , and 100) of amorphous $\mathrm{TiO}_{2}$ at $120^{\circ} \mathrm{C}$. SEM observation revealed an island growth of $\mathrm{ALD} \mathrm{TiO}_{2}$ on NMC powders, implying that $\mathrm{TiO}_{2}$ grew preferentially on certain sites such as defects. Synchrotron X-ray fluorescence (XRF) further revealed that the coating was deposited uniformly on both NMC powders and other inactive materials like carbon black. To investigate the effects of the ALD $\mathrm{TiO}_{2}$, we conducted a series of potentiostatic hold experiments using NMC/Li halfcells with and without the $\mathrm{ALD} \mathrm{TiO}_{2}$ coating from 4.1 to $4.6 \mathrm{~V}$ versus $\mathrm{Li} / \mathrm{Li}^{+}$. The experiments revealed that all the coated cells had lower static leakage currents compared to those of the bare electrodes. The smaller current values indicate a slower electron transfer reaction and less solvent oxidation in a unit time. Interestingly, all the coated cells had almost identical behavior. In other words, a coating of 20 ALD cycles could successfully mitigate the oxidation of the electrolyte, while a thicker coating did not further reduce static leakage currents. This finding is significant, for it suggests that the interfacial parasitic reactions mainly occur on the reactive sites on the NMC surface and these reactive sites have been effectively modified by the deposition of $\mathrm{TiO}_{2}$ even with a small number of ALD cycles. Moreover, we further compared the cyclability of $\mathrm{NMC} / \mathrm{Li}$ half-cells with and without the ALD $\mathrm{TiO}_{2}$ coating. Consequently, we observed a noticeable difference in terms of capacity retention at 4.4 and $4.5 \mathrm{~V}$ versus $\mathrm{Li} / \mathrm{Li}^{+}$[Fig. 8(a)], showing an evident enhancement due to the 20-cycle ALD coating (i.e., ALD-20). Furthermore, we verified this enhancement in NMC/graphite full cells [Fig. 8(b)]. These results apparently verify that minimizing parasitic reactions is critical for achieving durable NMC electrodes. We also conducted elemental mapping on cycled graphite anodes and found that there had less transition metal elements on the graphite electrode when the ALD-coated NMC electrode was used in the full cell [Fig. 8(c)]. In other words, the ALD coating protected NMC cathodes from leaching transition metals. The cycled NMC cathodes also were observed using SEM and the cycled bare cathode was found evident particle fragmentation [Fig. 8 (d)]. In addition, it also was found that the ALD coating could inhibit the average discharge voltage from decay [Fig. 8 (e)]. Apparently, the ALD $\mathrm{TiO}_{2}$ coating is beneficial to the NMC622 electrodes in multiple aspects.

The issues of NMC811 are more challenging than those of NMC622. In this regard, a recent work confirmed that infusing the grain boundaries (GBs) of NMC powders through annealing ALD-coated NMC powders could dramatically mitigate the formation of intergranular and intragranular cracks, stabilize NMC structures and interfaces, and thereby improve the performance of the coated NMC electrodes [140]. In the study, the ALD $\mathrm{Li}_{3} \mathrm{PO}_{4}$ coating was employed, which is an iSE [17]. 


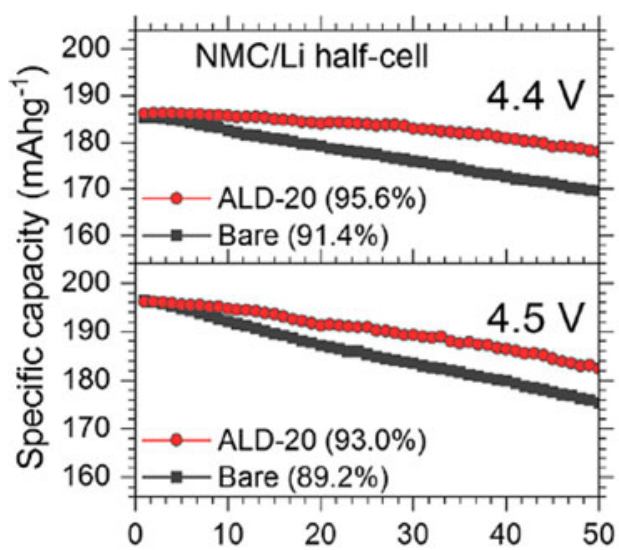

(a)

Cycle number

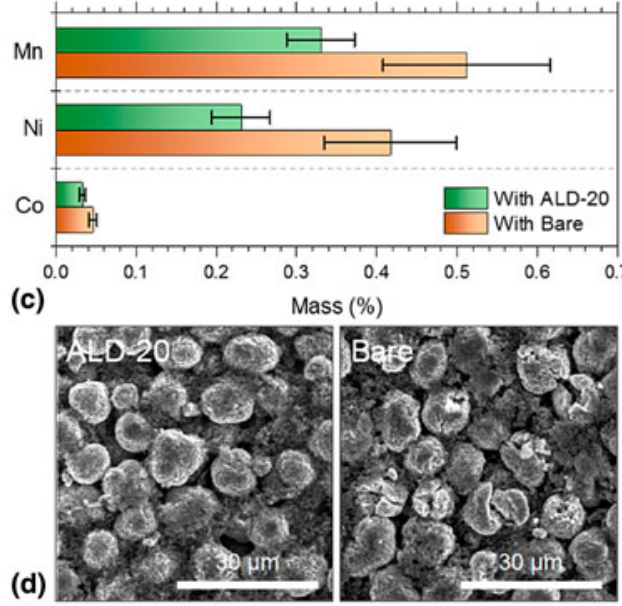

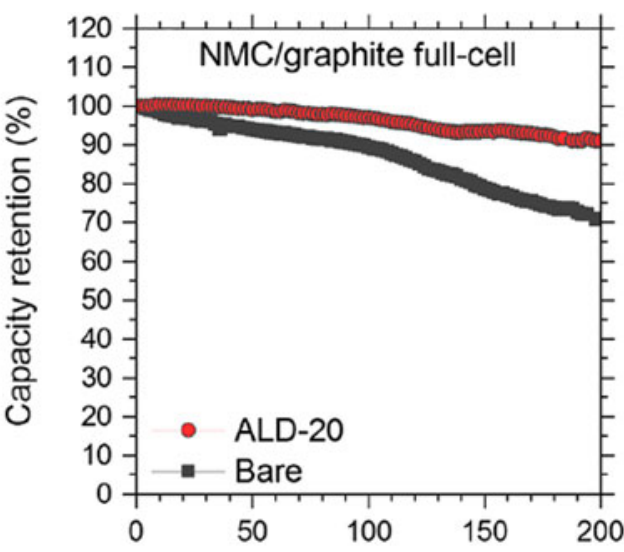

(b)

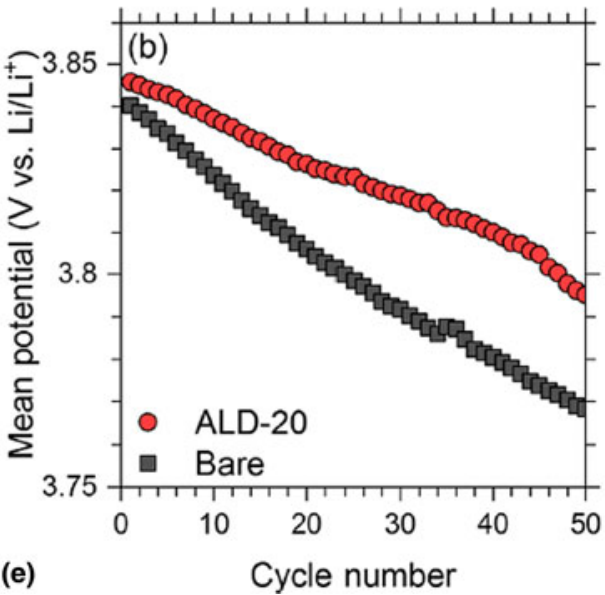

Figure 8: Effects of ALD TiO 2 coating on the NMC622 cathode [102]. (a) Cycling performance of NMC/Li half-cells using 20 ALD cycle-treated and bare NMC electrodes at 4.4 and $4.5 \mathrm{~V}$ versus $\mathrm{Li} / \mathrm{Li}^{+}$under a C/10 current density. (b) Cycling performance of NMC/graphite full cells using 20 ALD cycle-treated and bare NMC electrodes at $4.45 \mathrm{~V}$ versus $\mathrm{Li} / \mathrm{Li}^{+}$under a $\mathrm{C} / 3$ current density. (c) Quantification of the amount of $\mathrm{Mn}, \mathrm{Ni}$, and Co detected on the surface of graphite negative electrodes recovered from cycled NMC/graphite full cells coupled with and without surface-modified NMC electrodes (2 $\sigma$ absolute error). (d) SEM images of the NMC positive electrodes with and without surface modification recovered from cycled NMC/graphite full cells. (e) Variation of the average discharge potential of NMC electrodes with and without chemical modifications cycled at 4.4 V versus Li/Li+ $(C-$ rate $=0.1)$. Reprinted with permission from Ref. [102]. Copyright (2019) American Chemical Society.

This GB engineering approach was later further coupled with a second ALD coating by Cheng et al. [141]. In their work, Cheng et al. first coated NMC811 powder with a 5-nm thick $\mathrm{Li}_{3} \mathrm{PO}_{4}$ via $\mathrm{ALD}$ at $300^{\circ} \mathrm{C}$ and then the coated powders were annealed at $600{ }^{\circ} \mathrm{C}$ for $2 \mathrm{~h}$ to obtain the ALD-coated grain boundary sample (LPO@GB) [Fig. 9(a)]. The LPO@GB sample was further coated with LPO via the ALD LPO process to acquire the LPO@GB/Surface sample [Fig. 9(b)]. In the work, Cheng et al. investigated the individual effects of surface coating and GB engineering and revealed that both showed comparable improvement in performance in the voltage range of 2.7$4.3 \mathrm{~V}$. The capacity retentions were for $83 \%, 92 \%$, and $92 \%$ for the pristine, surface-coated, and GB engineered samples, respectively. Cycling in a voltage range of $2.7-4.5 \mathrm{~V}$, then the LPO@GB sample was better than the LPO@Surface sample, accounting for $85 \%$ versus $78 \%$ in capacity retention after 200 charge-discharge cycles. The bare sample only had a retention of 53\%. Cheng et al. [141] further investigated the coupling effects of surface coating and GB engineering. They found that the LPO@GB/Surface could realize a retention of $91 \%$ after 200 cycles in the voltage range of $2.7-4.7 \mathrm{~V}$ at a current rate of $1 / 3 \mathrm{C}$, much better than $61 \%$ for the LPO@GB sample after 200 cycles and $63 \%$ for the pristine sample after 100 cycles [Fig. 9(c)]. Apparently, the coupling protocol is very effective in improving NMC performance. Cross-sectional SEM images also confirmed that, cycled in the range of 2.7$4.7 \mathrm{~V}$, both the pristine and LPO@GB sample had serious fragmentation, while the LPO@GB/Surface sample had much fewer cracks. Cross-sectional TEM analyses revealed that the pristine NMC811 had a thick rock-salt surface layer after 100 cycles [Figs. 9(d1)-9(d3)] and the LPO@GB had alleviated structural changes (cracking and surface phase transition layer) (Figs. 9 (e1)-9(e3)]. In sharp contrast, the LPO@GB/Surface did not show structural evolutions [Figs. 9(f1)-9(f3)]. This work 
(a)
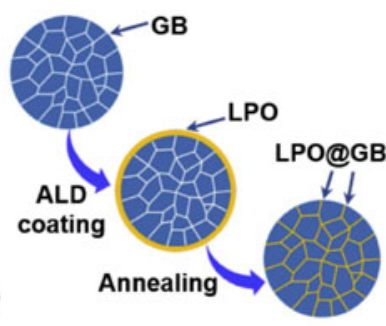

(b)
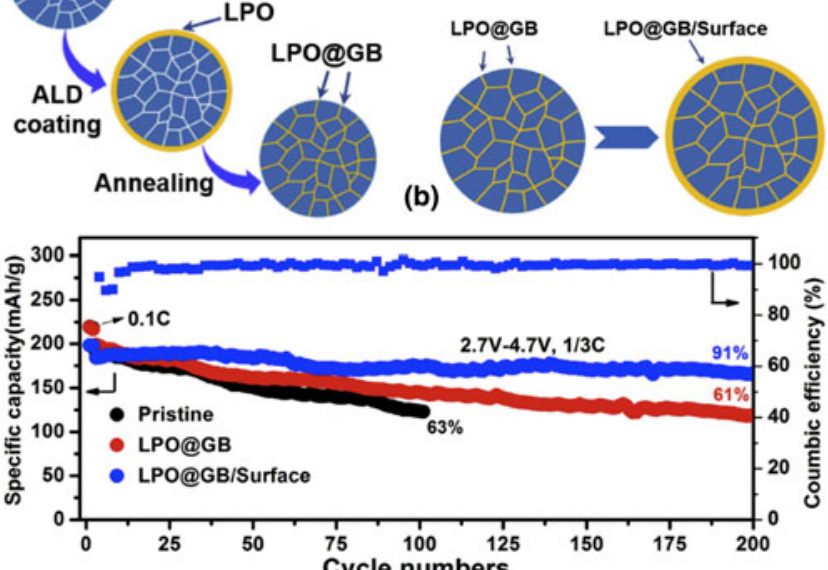
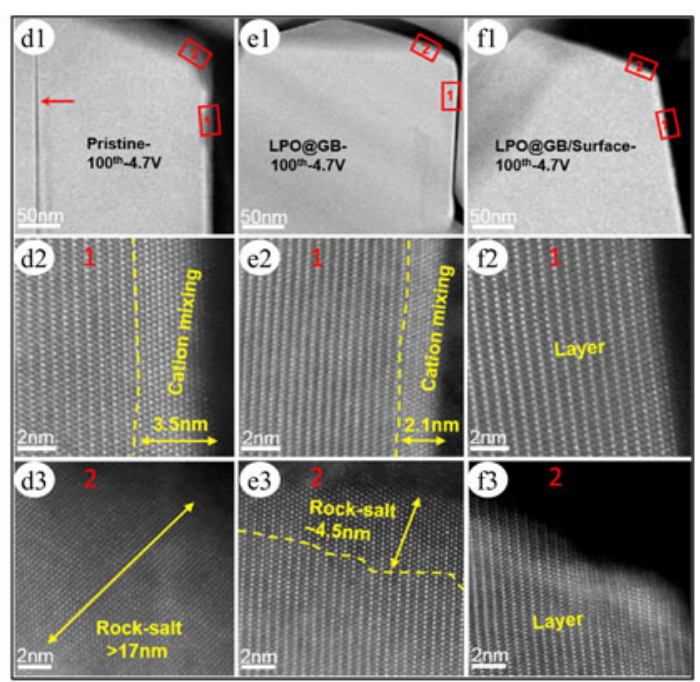

Figure 9: A new protocol for improving the electrochemical performance of NMC811 [141]. (a) A schematic illustration shows ALD coating and a subsequent annealing process to realize surface coating and GB engineering. (b) Coating a thin LPO layer on the LPO@GB sample to obtain the LPO@GB/Surface sample. (c) Capacity retention comparisons of the pristine sample, the LOP@GB sample, and the LPO@GB/surface sample. The half-cells were cycled at 2.7-4.7 V. STEM-HDDF images from (d1-d3) the pristine samples, (e1-e3) the LPO@GB sample, and (f1-f3) the LPO@GB/Surface sample after 100 cycles in the voltage range of 2.7-4.7 V. Reprinted with permission from Ref. [141]. Copyright (2019) Elsevier.

demonstrated that surface phase transformation and mechanical cracks are two major deleterious degradation mechanisms. To this end, the coupled GB surface coating protocol is very promising for addressing these issues.

\section{Advances in lithium batteries}

Lithium batteries mainly are $\mathrm{Li}-\mathrm{S}$ and $\mathrm{Li}-\mathrm{O}_{2}$ batteries, both using lithium metal as anodes. The two advanced battery systems use sulfur and oxygen as cathodes, respectively. Previously, we have conducted a comprehensive account [18] on the efforts of ALD and MLD for better Li-S batteries and readers may refer to it for more details. On the oxygen cathodes of $\mathrm{Li}-\mathrm{O}_{2}$ batteries, ALD has mainly been used for depositing nanoscale catalysts $[19,143,144]$ in several studies. In comparison, currently, there has an increasing number of studies on $\mathrm{Li}$ metal anodes, focusing on addressing dendritic growth and SEI formation. Thus, we herein primarily highlight the recent advances in Li metal anodes via ALD and MLD.

Li metal as an anode enables an extremely high capacity of $3860 \mathrm{mAh} / \mathrm{g}$ and also has a low electrochemical potential (i.e., $-3.04 \mathrm{~V}$ versus standard hydrogen electrode). Thus, lithium metal is an ideal anode material. However, Li metal anodes are prone to grow into dendritic structures to endanger battery cells and to continuously form SEI with the electrolyte depletion and cell impedance increase. As a result, a battery cell with an Li anode often exhibits low CEs and evident capacity fading. To address these issues, many strategies have been developed, such as electrolyte modification, SEs, artificial SEI, separator modification, and Li metal framework design [145].
The first report of ALD on modifying $\mathrm{Li}$ anodes was reported by Kozen et al. [146], in which nanoscale $\mathrm{Al}_{2} \mathrm{O}_{3}$ films were deposited on $\mathrm{Li}$ metal as a protective coating. Several subsequent studies [147, 148] have further explored the effects of $\mathrm{ALD} \mathrm{Al}_{2} \mathrm{O}_{3}$ coating. Different from the insulating ALD $\mathrm{Al}_{2} \mathrm{O}_{3}$ coating, we first applied an ionically conductive coating $\mathrm{Li}_{x} \mathrm{Al}_{y} \mathrm{~S}$ (having an ionic conductivity of $2.5 \times$ $10^{-7} \mathrm{~S} / \mathrm{cm}$ at RT) over Li metal as a protective layer [105], which was 50 -nm thick and deposited by combining two individual sub-ALD processes of $\mathrm{Li}-\mathrm{S}$ [109] and Al-S [90] in a cycle ratio of $1: 1$. Testing in symmetric Li/oLE/Li cells, the pristine $\mathrm{Li}$ symmetric cell had an $R_{\mathrm{SEI}}$ value of $\sim 2500 \Omega$, around five times higher than that of the coated $\mathrm{Li}$ symmetric cell after 68-h storage [Fig. 10(a)]. This implied that the ALD $\mathrm{Li}_{x} \mathrm{Al}_{y} \mathrm{~S}$ layer could protect the $\mathrm{Li}$ anodes from direct contact with the oLE. We further investigated the effects of the 50 -nm $\mathrm{ALD} \mathrm{Li}_{x} \mathrm{Al}_{y} \mathrm{~S}$ layer on cycling asymmetric $\mathrm{Li} / \mathrm{Cu}$ asymmetric cells. In the $\mathrm{Li} / \mathrm{Cu}$ cells, we compared the cells' performance due to the adoption of pristine and $\mathrm{Li}_{x} \mathrm{Al}_{y} \mathrm{~S}$-coated $\mathrm{Cu}$ foils. The $\mathrm{Li} /$ pristine $\mathrm{Cu}$ cell showed a gradually decreasing CE over the first 90 cycles, followed by a quick drop at around 135 cycles [Fig. 10(b)]. In comparison, the $\mathrm{Li} / \mathrm{Li}_{x} \mathrm{Al}_{y} \mathrm{~S}$-coated $\mathrm{Cu}$ cell enabled a very stable CE for 170 cycles [Fig. 10(b)]. Very encouragingly, we observed the deposition of $\mathrm{Li}$ on the pristine and $\mathrm{Li}_{x} \mathrm{Al}_{y} \mathrm{~S}$-coated $\mathrm{Cu}$ foils and found that there had numerous long filaments on the pristine $\mathrm{Cu}$ foil [Figs. 10(c) and $10(\mathrm{e})]$, while there had no obvious $\mathrm{Li}$ dendritic structures on $\mathrm{Li}_{x} \mathrm{Al}_{y} \mathrm{~S}$-coated $\mathrm{Cu}$ [Figs. 10(d) and 10(f)]. This work well demonstrated that the ALD $\operatorname{Li}_{x} \mathrm{Al}_{y} \mathrm{~S}$ layer enabled to stabilize the interface between the Li metal anode and electrolyte and 
(a)
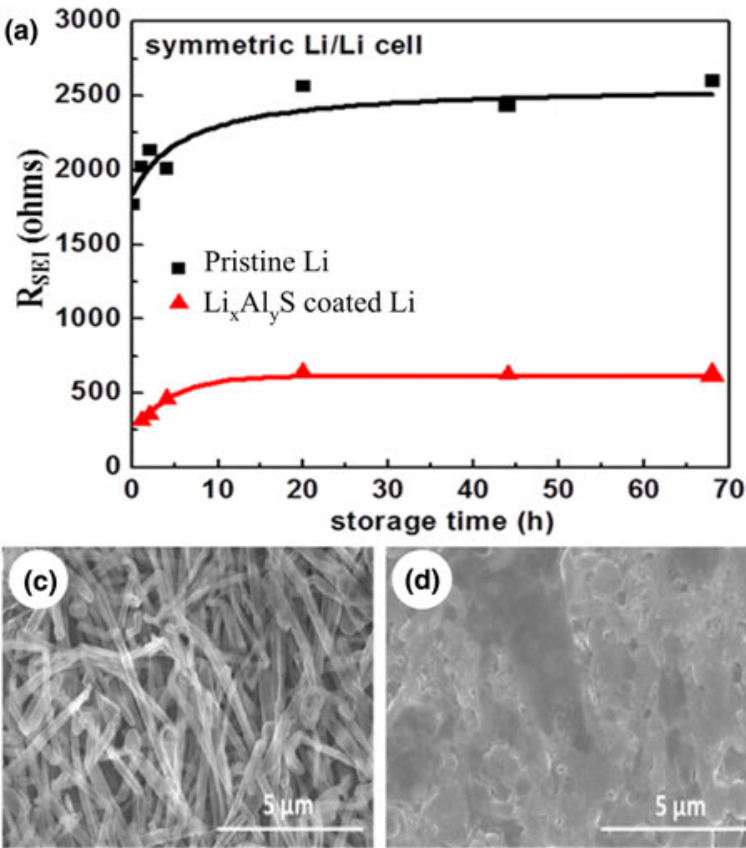

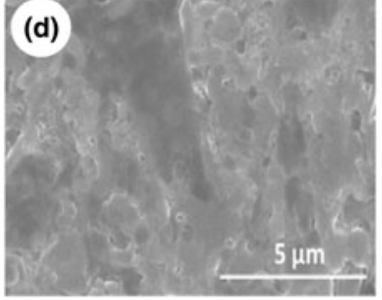

(b)
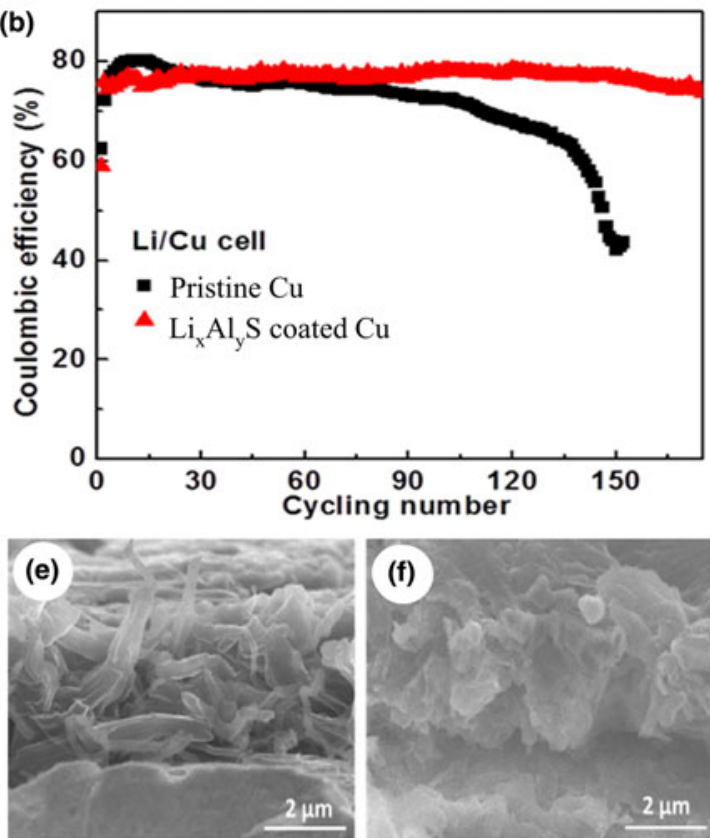

Figure 10: Effects of ALD Li $\mathrm{Al}_{y} \mathrm{~S}$ on Li metal anodes [105]. (a) $R_{\mathrm{SEl}}$ of Li/electrolyte/Li symmetric cells versus storage time. (b) CE of Li platting/stripping in 1M LiPF 6 in 3:7 EC:EMC. (c,d) Top-view and (e,f) cross-sectional SEM images of Li metal deposited on (c,e) pristine Cu and (d,f) Cu coated with a 50-nm Li $\mathrm{Al}_{x} \mathrm{~S}$ ALD film. Reprinted (adapted) with permission from Ref. [105]. Copyright (2016) John Wiley and Sons.

to inhibit the formation of $\mathrm{Li}$ dendritic structures, due to its good ionic conductivity. These favorable effects were later verified in our subsequent work [149], in which in situ electrochemical scanning transmission electron microscopy (EC-STEM) was used to directly visualize Li deposition and stripping with and without the $\mathrm{ALD} \mathrm{Li}_{x} \mathrm{Al}_{y} \mathrm{~S}$ protective coating. Our study revealed that Li self-discharge could be suppressed by the $50-\mathrm{nm} \mathrm{ALD} \mathrm{Li}_{x} \mathrm{Al}_{y} \mathrm{~S}$ protective coating.

Besides ALD coatings, MLD recently has shown very promising applications in modifying $\mathrm{Li}$ metal anodes and some efforts have emerged in the past 2 years. In one early study in 2018, Zhao et al. [117] conducted a study on alucone films deposited on Li metal for different cycles $(5,10,25$, and $50)$ at $120^{\circ} \mathrm{C}$. Accordingly, the films were named as, i.e., Li@5Alucone, Li@10Alucone, Li@25Alucone, and Li@50Alucone. Their thickness was 2.5, 5, 10, and $25 \mathrm{~nm}$, respectively. In the work, Zhao et al. [117] first investigated the cycling performance of the bare $\mathrm{Li}$ and alucone-coated $\mathrm{Li}$ in symmetric cells using an ether-based electrolyte. At $5 \mathrm{~mA} / \mathrm{cm}^{2}$, the overpotential of the bare $\mathrm{Li}$ was initially $80 \mathrm{mV}$, then increased suddenly to $160 \mathrm{mV}$ after 20 cycles, and fluctuated in the following cycles. In contrast, the overpotential of the Li@10Alucone was 100 mV initially and then stabilized and persisted at $70 \mathrm{mV}$ over 100 cycles. Zhao et al. [117] further comparatively investigated the effects of the bare $\mathrm{Li}$ anode and the alucone-coated $\mathrm{Li}$ anode on the performance of Li-S batteries. They found that, using the bare $\mathrm{Li}$ anode, the $\mathrm{Li}-\mathrm{S}$ cell exhibited a capacity fade. In comparison, using the alucone-coated $\mathrm{Li}$ anode, the Li-S cell stabilized in 10 cycles, and the $\mathrm{S}$ cathode could deliver a high capacity $\left(711 \mathrm{mAh} / \mathrm{cm}^{2}\right)$ and CE (95\%) after 100 cycles. Therefore, one could conclude that the alucone coating has helped prolong the cell life and realize better sulfur utilization by preventing the interaction between polysulfide and Li. Using SEM, Zhao et al. [117] noticed that, after 30 plating/stripping cycles, the bare $\mathrm{Li}$ anode showed a rough surface with $\mathrm{Li}$ dendrites, whereas the alucone-coated $\mathrm{Li}$ anode could only be observed with a nodule-like structure. Furthermore, Zhao et al. [117] studied the electrochemical behaviors of the bare $\mathrm{Li}$ and the alucone-coated $\mathrm{Li}$ anodes in a carbonate-based electrolyte. They found that the voltage profiles of the bare Li foil fluctuated dramatically after $300 \mathrm{~h}$ cycling, implying the continuous increase of resistance and the presence of short circuit. In contrast, the voltage profiles of the alucone-coated $\mathrm{Li}$ anode were much more stable. The Li@50Alucone performed the best in all the symmetric cells, including the bare Li, Li@10Alucone, Li@25Alucone, and Li@50Alucone. Obviously, the optimal thickness of the alucone layer varies with electrolytes, accounting for $10 \mathrm{MLD}$ alucone cycles $(5 \mathrm{~nm})$ for the ether-based electrolyte while $50 \mathrm{MLD}$ alucone cycles $(25 \mathrm{~nm})$ for the carbonate-based electrolyte. In addition, Zhao et al. [117] compared the effects of $\mathrm{ALD} \mathrm{Al}_{2} \mathrm{O}_{3}$ and MLD alucone coatings. They revealed that, in the carbonate electrolyte, the bare $\mathrm{Li}$ only survived for $300 \mathrm{~h}$. In comparison, the $\mathrm{Li} 25 \mathrm{Al}_{2} \mathrm{O}_{3}$ (2.5 nm, the optimal thickness) and Li@50Alucone outperformed the bare $\mathrm{Li}$ anode. More encouragingly, the 


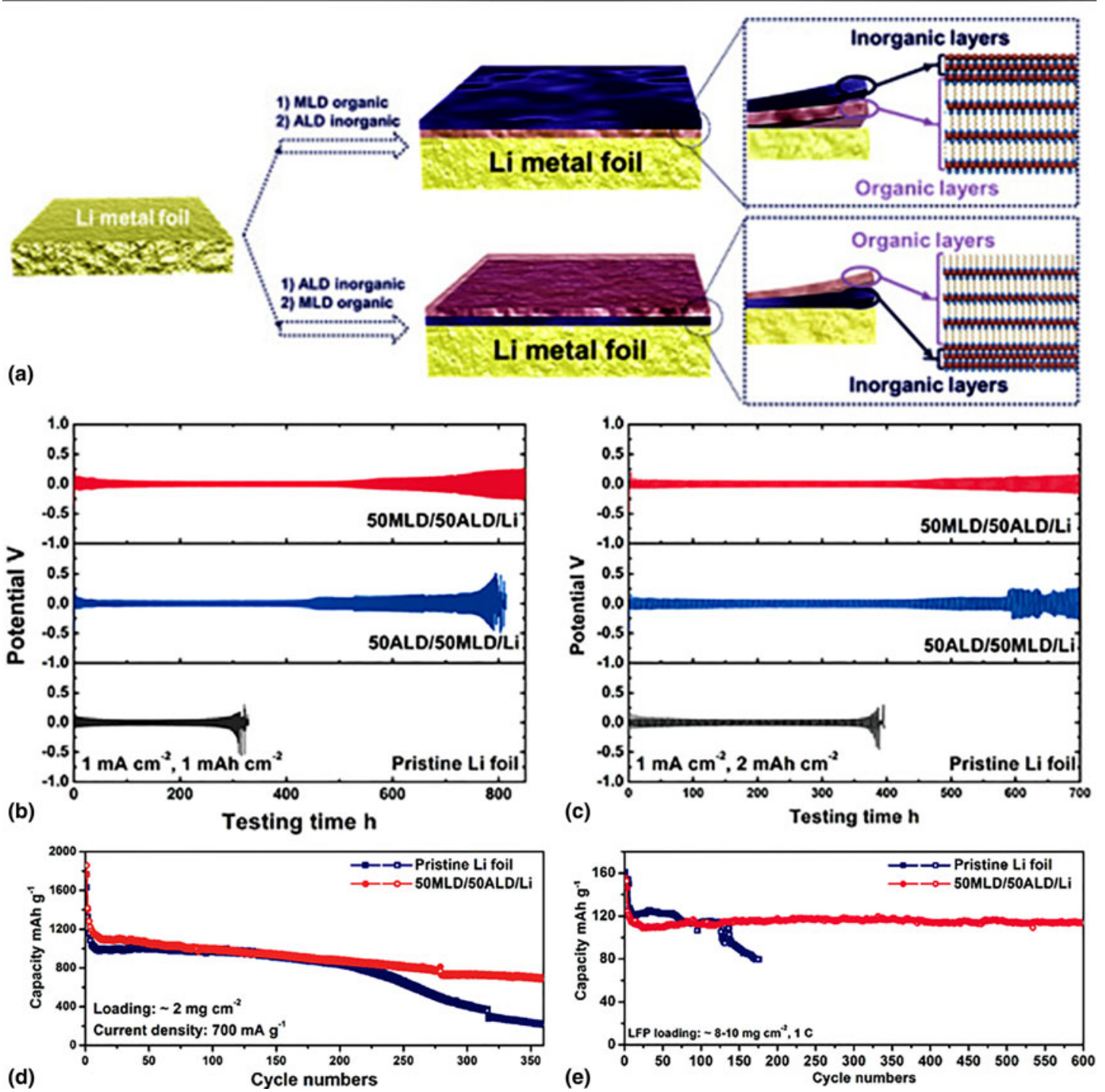

Figure 11: The dual protective layers by ALD and MLD and their effects [152]. (a) Schematic illustration of the fabrication process of the dual protective layer by ALD and MLD. (b and c) The overpotential of Li/Li symmetric cells using pristine Li foil, 50ALD/50MLD/Li, and 50MLD/50ALD/Li in a carbonate electrolyte. Cycling performance of (d) Li-S and (e) Li-LFP full cells. Reprinted with permission from Ref. [152]. Copyright (2019) Elsevier.

Li@50Alucone anode enabled the best performance with more stable voltage profiles. Thus, it was believed that the alucone layer was robust enough against the electrolyte, mechanically flexible to accommodate repeated $\mathrm{Li}$ plating/stripping, and highly ionic conductive for $\mathrm{Li}^{+}$transfer.

In a later study, Adair et al. [150] investigated an MLD zircone film as the protective layer over Li metal anodes. Similar to the effects of the alucone in the study of Zhao et al. [117], this zircone layer could well stabilize the surface of Li metal anodes and helped realize long-term stable cyclability. The zircone-coated $\mathrm{Li}$ anodes were further demonstrated in $\mathrm{Li}-\mathrm{O}_{2}$ cells. The cell with a bare $\mathrm{Li}$ anode was unstable and showed micro-short circuiting in less than $50 \mathrm{~h}$. In contrast, the cell with a zircone-coated $\mathrm{Li}$ anode enabled significantly enhanced electrochemical stability and lifetime, accounting for $500 \mathrm{~h}$ with little change in voltage polarization. In another subsequent study, Sun et al. [151] also demonstrated that a polyurea layer via MLD could help improve the stability and lifetime of Li metal anodes. Very interestingly, recently Zhao et al. [152] developed bilayered hybrid protective films consisting of an MLD-deposited organic layer and an ALD deposited inorganic layer [Fig. 11(a)]. This combination features tunable layer thickness and property to achieve the optimal protection effects. In $\mathrm{Li} / \mathrm{Li}$ symmetric cells using a carbonate electrolyte, they found that the 50MLD/50ALD/Li performed the best, compared to the $50 \mathrm{ALD} / 50 \mathrm{MLD} / \mathrm{Li}$ and the bare samples at different testing conditions [Figs. 11(b) and 11(c)]. Using an ether electrolyte instead, the 50MLD/50ALD/Li still exhibited the best performance. Furthermore, the 50MLD/50ALD/Li anodes were used to couple with a sulfur cathode and an 


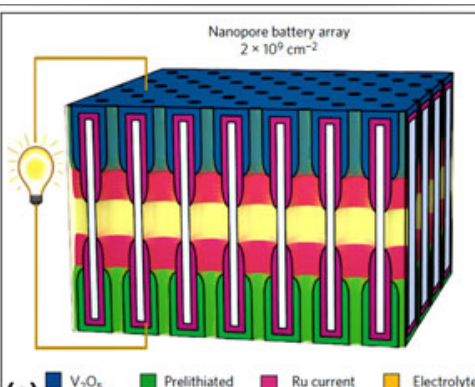

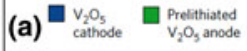

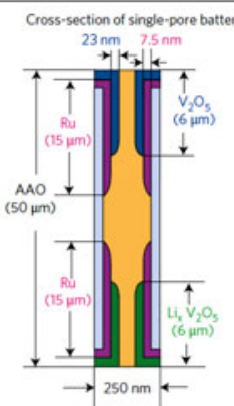

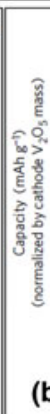

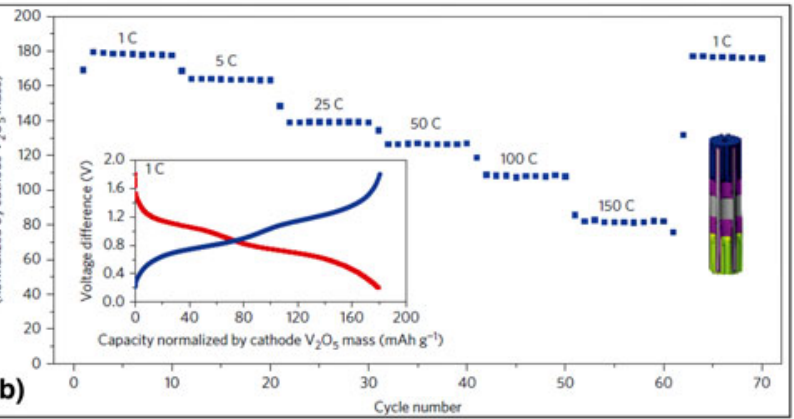

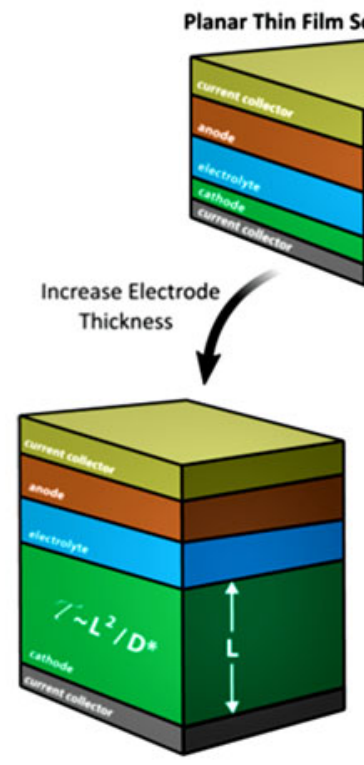

Cell Footprint $=\boldsymbol{A}_{\boldsymbol{f}}$ Internal Interface Area $=A$

(c) (c) Energy $\uparrow$ Power $\downarrow$

\section{Solid State Battery}
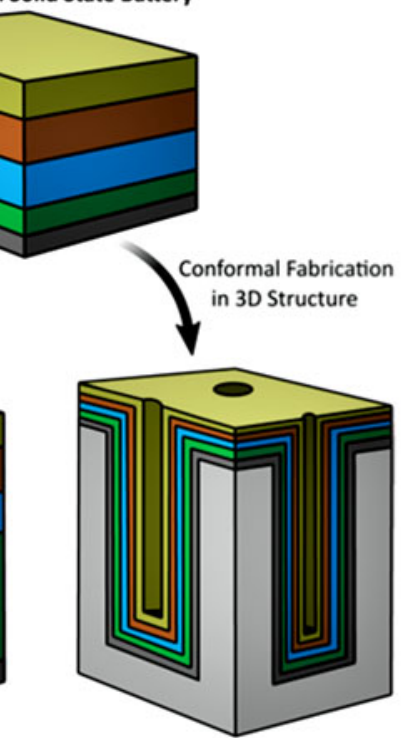

Cell Footprint $=A_{f}$ Internal Interface Area $>A$

Energy $\uparrow$ Power $\uparrow \hat{A}$

(d)
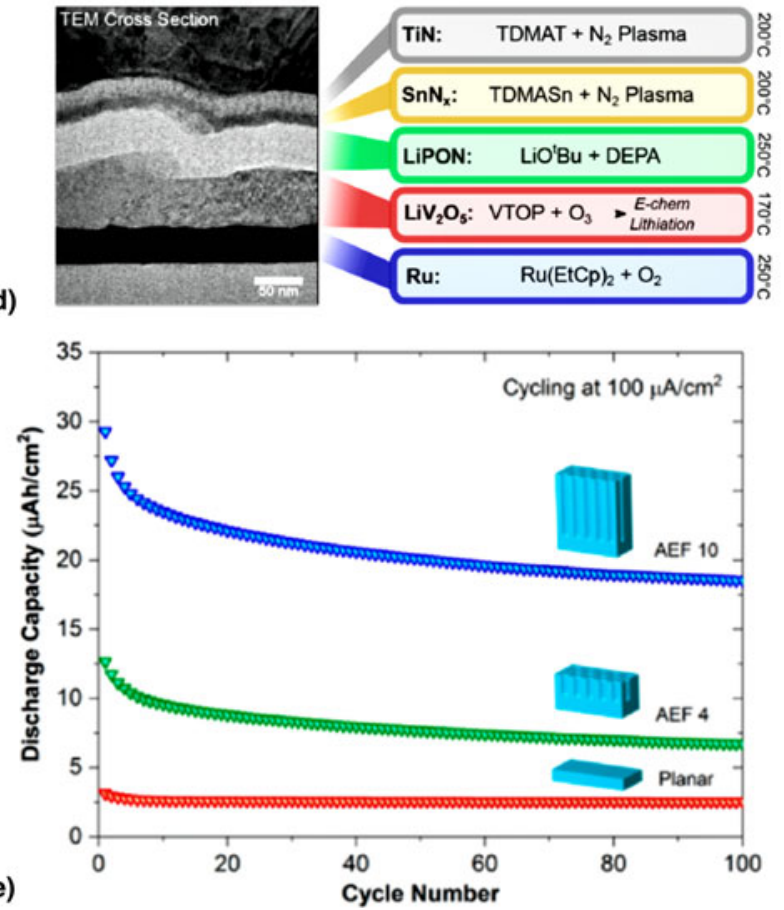

Figure 12: $3 \mathrm{D}$ microbatteries via ALD. (a) Schematic illustration of parallel nanopore battery array and cross section of a single-pore battery, consisting of a $\mathrm{V}_{2} \mathrm{O}_{5}$ cathode, a prelithiated $\mathrm{V}_{2} \mathrm{O}_{5}$ anode, two Ru current collectors, and an oLE [96]. (b) Rate performance of the nanopore battery array (inset: charge and discharge profiles at 1C) [96]. Reprinted with permission from Ref. [96]. Copyright (2014) Springer Nature. (c) Methods of improving energy storage metrics for thin-film solid-state batteries. Increasing the electrode thickness scales energy density at the expense of power density due to the rapid increase in the characteristic diffusion time for ions in the thick electrode. Fabricating thin-film solid-state batteries in a 3D structure both increases areal material loading and increases power performance through a decrease in the internal current density due to the larger internal surface area [97]. (d) Cross-sectional TEM image of an all-ALD solid-state battery with 40-nm Ru/70-nm LiV $\mathrm{O}_{5} / 50-\mathrm{nm} \mathrm{Li}_{2} \mathrm{PO}_{2} \mathrm{~N} / 10-\mathrm{nm} \mathrm{SnN} \mathrm{S}_{x} / 25-\mathrm{nm}$ TiN [97]. (e) Electrochemical performance of 3D solid-state batteries: cycling performance of AEF 1, 4, and 10 batteries galvanostatically cycled 100 times at $100 \mu \mathrm{A} / \mathrm{cm}^{2}$ [97]. Reprinted with permission from Ref. [97]. Copyright (2018) American Chemical Society.

LFP cathode in full cells. Compared to the pristine Li foil, the $50 \mathrm{MLD} / 50 \mathrm{ALD} / \mathrm{Li}$ enabled much better performance for the full cells of Li-S [Fig. 11(d)] and Li-LFP [Fig. 11(e)], in terms of sustainable capacity and cyclability.

\section{Advances in solid-state batteries}

In addition to tailoring interfaces of liquid cells as discussed above, ALD and MLD also emerged as new thrusts to modify interfaces of solid-state batteries. Some latest progresses of ALD in interface-tailoring solid-state batteries have been discussed in the recent review article by Meng [17]. Very importantly, ALD and MLD are two important tools for fabricating thin film batteries, especially 3D microbatteries. 3D solid-state microbatteries have long been pursued in autonomous systems (e.g., pacemakers) for higher energy and power with reliable safety. In the past decade, ALD and MLD have made many encouraging advances. ALD and MLD have achieved many processes for growing anodes, cathodes, and iSEs. Meng recently has made a special survey on iSEs via ALD [17]. There also have been a variety of anodes reported to date via $\mathrm{ALD}$ and they are typically binary (e.g., $\mathrm{TiO}_{2}$, $\mathrm{SnO}_{2}, \mathrm{ZnO}$, and $\mathrm{Fe}_{2} \mathrm{O}_{3}$ ) or single elements ( $\mathrm{Si}, \mathrm{Sn}$, and $\left.\mathrm{Ge}\right)$. In comparison, it is more challenging to develop LIB cathodes 
via ALD, for they are typically ternary or quaternary. In this section, thus, we will brief on the achievements of ALD in LIB cathodes as well as the recent MLD emergence for LIB electrodes. Then, we will highlight two prototypes of 3D microbatteries by ALD.

The first ALD report on the LIB cathode was also the first work of ALD in batteries, which was done by Badot et al. in 2000 [77]. In the work, $\mathrm{V}_{2} \mathrm{O}_{5}$ nanofilms were synthesized and electrochemically tested for lithium-storage. Since that time until 2011, there had a second process for LIB cathodes in which LCO was grown via plasma-enhanced ALD (PE-ALD) [153]. Subsequently, amorphous $\mathrm{FePO}_{4}$ [154], polycrystalline $\mathrm{Li}_{x} \mathrm{Mn}_{2} \mathrm{O}_{4}$ [155], and $\mathrm{LiFePO}_{4}$ [92] were reported. Along with the development of LIB cathodes, there have been lithium-conductive iSEs reported since 2009, as summarized by Meng [17]. In addition to LIB cathodes, Meng et al. have succeeded in synthesizing $\mathrm{Li}_{2} \mathrm{~S}$ as a cathode in $\mathrm{Li}-\mathrm{S}$ batteries [109]. Recently, there also has one attempt using MLD for an LIB anode, in which a crystalline hybrid polymer, lithium terephthalate (LTP) was synthesized and electrochemically verified [120].

With the successes in battery materials as anodes, cathodes, and iSEs, there have been many efforts for solid-state microbatteries. In this regard, there have two excellent architectures for 3D microbatteries from previous ALD efforts. One was reported in 2014, in which $\mathrm{Ru}$ metal films were deposited into nanopores of anodic aluminum oxide (AAO) templates in two ends as current collectors via ALD. Then, $\mathrm{V}_{2} \mathrm{O}_{5}$ nanofilms also were deposited via ALD in two ends and they were over the $\mathrm{Ru}$ films [Fig. 12(a)]. One end was prelithiated. Then, the nanopores were infused with a traditional oLE. This architecture could realize high power, high rate performance, and high capacity retention [Fig. 12(b)]. More recently, a new 3D microbattery realized all-solid-state, in which an SE replaced traditional oLEs [Fig. 12(c)] [97]. It is the first time that a $3 \mathrm{D}$ microbattery was fully deposited by ALD, consisting of five layers, $\mathrm{Ru}$ metal as the cathode current collector, $\mathrm{LiV}_{2} \mathrm{O}_{5}$ as the cathode, LiPON as the iSE, $\mathrm{SnN}_{x}$ as the anode, and TiN as the anode current collector [Fig. 12(d)]. This all-solid-sate $3 \mathrm{D}$ microbattery could realize higher capacity with a higher area enhancement factor (AEF), where $\mathrm{AEF}=A / A_{\mathrm{f}}(A$ is the internal cell interface area, while $A_{\mathrm{f}}$ is the cell footprint area) [Fig. 12(e)].

To sum up, there have a large number of successes in ALD processes for battery materials, which make possible to integrate different functional films to develop 3D solid-state batteries, due to its unique capability to form conformal coatings over HAR structures. All these have made ALD an appealing technique to advance $3 \mathrm{D}$ solid-state microbattery technology.

In addition to the progresses discussed above for LIBs, lithium metal batteries, and 3D solid-state microbatteries, there have some new trends emerging for other beyond LIB systems, including sodium-based [20], zinc-based [113], potassiumbased [156], aluminum-based [114], and magnesium-based batteries [157]. Meng has made an updated overview of ALD for SIBs [20]. The other new trends are still at their very early stages. With more efforts invested in the coming years, we are expecting to see many more excitements delivered using ALD and MLD.

\section{Concluding remarks}

This review represents the first comprehensive survey on summarizing the pursuit of ALD and MLD for better batteries in the past two decades. The exceptional and unique benefits of ALD and MLD lie in several aspects: (i) atomic-/molecularscale rational design, (ii) in situ growth of unrivaled uniform and conformal pinhole-free films, (iii) high flexibility for nearly any materials, and (iv) low process temperature. All these have made ALD and MLD two compelling techniques for pursuing better batteries. In this review, we highlighted both ALD and MLD capabilities and applications in LIBs, lithium metal batteries, solid-state batteries through discussing some typical case studies. In exploring the capabilities of ALD and MLD in LIBs and beyond, we have been mainly utilizing them in two aspects: (i) design of nanostructured battery components and (ii) nanoscale tailoring battery interfaces. All these are beneficial to achieve improved battery performance. We further noticed and pointed out the new research trends of ALD and MLD in sodium-, potassium, zinc-, aluminum-, and magnesium-based batteries. All these have well witnessed the efforts of ALD and MLD in pursuing better batteries. With this article, we would expect that ALD and MLD will bring many more new breakthroughs in advanced battery technologies in the coming decade.

\section{Acknowledgments}

X.M. acknowledges partial support from the Center for Advanced Surface Engineering, under the National Science Foundation Grant No. OIA-1457888 and the Arkansas EPSCoR Program, ASSET III. X.M. also appreciates the financial research support from the University of Arkansas, Fayetteville, AR, USA.

\section{References}

1. M.M. Thackeray, C. Wolverton, and E.D. Isaacs: Electrical energy storage for transportation-approaching the limits of, and going beyond, lithium-ion batteries. Energy Environ. Sci. 5, 78547863 (2012). 
2. M. Winter and R.J. Brodd: What are batteries, fuel cells, and supercapacitors? Chem. Rev. 104, 4245-4270 (2004).

3. M.S. Whittingham: History, evolution, and future status of energy storage. Proc. IEEE 100(Special Centennial Issue), 15181534 (2012)

4. D. Deng: Li-ion batteries: Basics, progress, and challenges. Energy Sci. Eng. 3, 385-418 (2015).

5. Y. Liang, C.-Z. Zhao, H. Yuan, Y. Chen, W. Zhang, J.-Q. Huang, D. Yu, Y. Liu, M.-M. Titirici, Y.-L. Chueh, H. Yu, and Q. Zhang et al.: A review of rechargeable batteries for portable electronic devices. InfoMat 1, 6-32 (2019).

6. G.J. May, A. Davidson, and B. Monahov: Lead batteries for utility energy storage: A review. J. Energy Storage 15, 145-157 (2018).

7. G. Crabtree, E. Kócs, and L. Trahey: The energy-storage frontier: Lithium-ion batteries and beyond. MRS Bull. 40, 1067-1078 (2015).

8. S. Zhang: Status, opportunities, and challenges of electrochemical energy storage. Front. Energy Res. 1, 8 (2013).

9. G.E. Blomgren: The development and future of lithium ion batteries. J. Electrochem. Soc. 164, A5019-A5025 (2017).

10. X. Judez, G. G. Eshetu, C. Li, L. M. Rodriguez-Martinez, H. Zhang, and M. Armand: Opportunities for rechargeable solid-state batteries based on Li-intercalation cathodes. Joule $\mathbf{2}$, 2208-2224 (2018).

11. X. Yu and A. Manthiram: Electrode-electrolyte interfaces in lithium-based batteries. Energy Environ. Sci. 11, 527-543 (2018).

12. M. Gauthier, T. J. Carney, A. Grimaud, L. Giordano, N. Pour, H.-H. Chang, D. P. Fenning, S. F. Lux, O. Paschos, C. Bauer, F. Maglia, S. Lupart, P. Lamp, Y. Shao-Horn et al.: Electrodeelectrolyte interface in Li-ion batteries: Current understanding and new insights. J. Phys. Chem. Lett. 6, 4653-4672 (2015).

13. S.M. George: Atomic layer deposition: An overview. Chem. Rev. 110, 111-131 (2010)

14. X. Meng: An overview of molecular layer deposition for organic and organic-inorganic hybrid materials: Mechanisms, growth characteristics, and promising applications. J. Mater. Chem. A 5, 18326-18378 (2017).

15. X. Meng, X.Q. Yang, and X.L. Sun: Emerging applications of atomic layer deposition for lithium-ion battery studies. $A d v$. Mater. 24, 3589-3615 (2012).

16. C. Zhu, K. Han, D. Geng, H. Ye, and X. Meng: : Achieving high-performance silicon anodes of lithium-ion batteries via atomic and molecular layer deposited surface coatings: An overview. Electrochim. Acta 251, 710-728 (2017).

17. X. Meng: Atomic layer deposition of solid-state electrolytes for next-generation lithium-ion batteries and beyond: Opportunities and challenges. Energy Storage Mater. 30, 296-328 (2020).

18. Q. Sun, K. C. Lau, D. Geng, and X. Menget al.: Atomic and molecular layer deposition for superior lithium-sulfur batteries:
Strategies, performance, and mechanisms. Batteries Supercaps 1, 41-68 (2018)

19. H.-S. Shin, G. W. Seo, K. Kwon, K.-N. Jung, S. I. Lee, E. Choi, H. Kim, J.-H. Hwang, and J.-W. Lee: A combined approach for high-performance $\mathrm{Li}-\mathrm{O}_{2}$ batteries: A binder-free carbon electrode and atomic layer deposition of $\mathrm{RuO}_{2}$ as an inhibitor-promoter. APL Mater. 6, 047702 (2018)

20. X. Meng: Atomic-scale surface modifications and novel electrode designs for high-performance sodium-ion batteries via atomic layer deposition. J. Mater. Chem. A 5, 10127-10149 (2017).

21. M. Armand and J.M. Tarascon: Building better batteries. Nature 451, 652-657 (2008).

22. K. Xu: Nonaqueous liquid electrolytes for lithium-based rechargeable batteries. Chem. Rev. 104, 4303-4418 (2004).

23. K. Xu: Electrolytes and interphases in Li-ion batteries and beyond. Chem. Rev. 114, 11503-11618 (2014).

24. R.C. Agrawal and G.P. Pandey: Solid polymer electrolytes: Materials designing and all-solid-state battery applications: An overview. J. Phys. D Appl. Phys. 41, 223001 (2008).

25. X. Chen and P.M. Vereecken: Solid and solid-like composite electrolyte for lithium ion batteries: Engineering the ion conductivity at interfaces. Adv. Mater. Interfaces 6, 1800899 (2019).

26. T. Famprikis, P. Canepa, J.A. Dawson, M. Saiful Islam, and C. Masquelier: Fundamentals of inorganic solid-state electrolytes for batteries. Nat. Mater. 18, 1278-1291 (2019).

27. Q. Zhao, S. Stalin, C.-Z. Zhao, and L. A. Archer: : Designing solid-state electrolytes for safe, energy-dense batteries. Nat. Rev. Mater. 5, 229-252 (2020)

28. N. Yabuuchi, K. Kubota, M. Dahbi, and S. Komaba: Research development on sodium-ion batteries. Chem. Rev. 114, 1163611682 (2014)

29. W. Zhang, Y. Liu, and Z. Guo: Approaching high-performance potassium-ion batteries via advanced design strategies and engineering. Sci. Adv. 5, eaav7412 (2019).

30. A. Ponrouch, J. Bitenc, R. Dominko, N. Lindahl, P. Johansson, and M. R. Palacin: Multivalent rechargeable batteries. Energy Storage Mater. 20, 253-262 (2019).

31. M. Winter: The solid electrolyte interphase - The most important and the least understood solid electrolyte in rechargeable $\mathrm{Li}$ batteries. Z. Phys. Chem. 223, 1395-1406 (2009).

32. Y. Xiao, Y. Wang, S.-H. Bo, J. C. Kim, L. J. Miara, and G. Ceder: Understanding interface stability in solid-state batteries. Nat. Rev. Mater. 5, 105-126 (2020).

33. T. Suntola and J. Antson: Method for producing compound thin films. United States Patent 4,058,430, 1977.

34. T. Yoshimura, S. Tatsuura, and W. Sotoyama: Polymer films formed with monolayer growth steps by molecular layer deposition. Appl. Phys. Lett. 59, 482-484 (1991). 
35. M.D. Groner, F. H. Fabreguette, J. W. Elam, and S. M. George: Low-temperature $\mathrm{Al}_{2} \mathrm{O}_{3}$ atomic layer deposition. Chem. Mater. 16, 639-645 (2004).

36. R.L. Puurunen: Surface chemistry of atomic layer deposition: A case study for the trimethylaluminum/water process. J. Appl. Phys. 97, 121301 (2005).

37. S.M. George, B. Yoon, and A.A. Dameron: Surface chemistry for molecular layer deposition of organic and hybrid organic -inorganic polymers. Acc. Chem. Res. 42, 498-508 (2009).

38. J. Hämäläinen, M. Ritala, and M. Leskelä: Atomic layer deposition of noble metals and their oxides. Chem. Mater. 26, 786-801 (2014).

39. H. Kim: Atomic layer deposition of metal and nitride thin films: Current research efforts and applications for semiconductor device processing. J. Vac. Sci. Technol. B 21, 2231-2261 (2003).

40. V. Miikkulainen, M. Leskelä, M. Ritala, and R. L. Puurunen: Crystallinity of inorganic films grown by atomic layer deposition: Overview and general trends. J. Appl. Phys. 113, 021301 (2013).

41. R.L. Puurunen: Surface chemistry of atomic layer deposition: A case study for the trimethylaluminum/water process. J. Appl. Phys. 97, 121301 (2005).

42. N.P. Dasgupta, X. Meng, J. W. Elam, A. B. Martinson, et al.: Atomic layer deposition of metal sulfide materials. Acc. Chem. Res. 48, 341-348 (2015).

43. Z. Guo and X. Wang: Atomic layer deposition of the metal pyrites $\mathrm{FeS}_{2}, \mathrm{CoS}_{2}$, and $\mathrm{NiS}_{2}$. Angew. Chem. Int. Ed. 57, 5898-5902 (2018).

44. J. Wang, Z. Guo, W. Xiong, and X. Wang: Synthesis of thin-film metal pyrites by an atomic layer deposition approach. Chemistry 24, 18568-18574 (2018).

45. M. Mäntymäki, M. Ritala, and M. Leskelä: Metal fluorides as lithium-ion battery materials: An atomic layer deposition perspective. Coatings 8, 277 (2018).

46. J. Cai, X. Han, X. Wang, and X. Meng: Atomic layer deposition of two-dimensional layered materials: Processes, growth mechanisms, and characteristics. Matter 2, 587-630 (2020).

47. H. Zhou and S.F. Bent: Fabrication of organic interfacial layers by molecular layer deposition: Present status and future opportunities. J. Vac. Sci. Technol. A 31, 040801 (2013).

48. H.-I. Shao, S. Umemoto, T. Kikutani, and N. Okui: Layer-by-layer polycondensation of nylon 66 by alternating vapour deposition polymerization. Polymer 38, 459-462 (1997).

49. Y. Du and S.M. George: Molecular layer deposition of nylon 66 films examined using in situ FTIR spectroscopy. J. Phys. Chem. C 111, 8509-8517 (2007)

50. T. Yoshimura, S. Tatsuura, W. Sotoyama, A. Matsuura, and T. Hayano: Quantum wire and dot formation by chemical vapor deposition and molecular layer deposition of one-dimensional conjugated polymer. Appl. Phys. Lett. 60, 268-270 (1992).
51. T. Yoshimura, A. Oshima, D.-I. Kim, and Y. Morita: Quantum dot formation in polymer wires by three-molecule molecular layer deposition (MLD) and applications to electro-optic/photovoltaic devices. ECS Trans. 25, 15-25 (2009).

52. T. Yoshimura, R. Ebihara, and A. Oshima: Polymer wires with quantum dots grown by molecular layer deposition of three source molecules for sensitized photovoltaics. J. Vac. Sci. Technol. A 29, 051510 (2011).

53. T. Yoshimura and S. Ishii: Effect of quantum dot length on the degree of electron localization in polymer wires grown by molecular layer deposition. J. Vac. Sci. Technol. A 31, 031501 (2013).

54. A. Kim, M. A. Filler, S. Kim, and S. F. Bent: Layer-by-layer growth on $\mathrm{Ge}(100)$ via spontaneous urea coupling reactions. J. Am. Chem. Soc. 127, 6123-6132 (2005).

55. P.W. Loscutoff, H. Zhou, S. B. Clendenning, and S. F. Bent: Formation of organic nanoscale laminates and blends by molecular layer deposition. ACS Nano 4, 331-341 (2010).

56. H. Zhou and S.F. Bent: Molecular layer deposition of functional thin films for advanced lithographic patterning. ACS Appl. Mater. Interfaces 3, 505-511 (2011).

57. H. Zhou, M.F. Toney, and S.F. Bent: Cross-linked ultrathin polyurea films via molecular layer deposition. Macromolecules 46, 5638-5643 (2013)

58. Y.-S. Park, S.-E. Choi, H. Kim, and J. S. Lee: Fine-tunable absorption of uniformly aligned polyurea thin films for optical filters using sequentially self-limited molecular layer deposition. ACS Appl. Mater. Interfaces 8, 11788-11795 (2016).

59. N.M. Adamczyk, A.A. Dameron, and S.M. George: Molecular layer deposition of poly(p-phenylene terephthalamide) films using terephthaloyl chloride and p-phenylenediamine. Langmuir 24, 2081-2089 (2008).

60. Q. Peng, K. Efimenko, J. Genzer, and G. N. Parsons: Oligomer orientation in vapor-molecular-layer-deposited alkyl-aromatic polyamide films. Langmuir 28, 10464-10470 (2012).

61. S.E. Atanasov, M. D. Losego, B. Gong, E. Sachet, J.-P. Maria, P. S. Williams, and G. N. Parsons: Highly conductive and conformal poly(3,4-ethylenedioxythiophene) (PEDOT) thin films via oxidative molecular layer deposition. Chem. Mater. 26, 34713478 (2014).

62. D.H. Kim, S. E. Atanasov, P. Lemaire, K. Lee, and G.N. Parsons: Platinum-free cathode for dye-sensitized solar cells using poly(3,4-ethylenedioxythiophene) (PEDOT) formed via oxidative molecular layer deposition. ACS Appl. Mater. Interfaces 7, 3866-3870 (2015).

63. T. Miyamae, K. Tsukagoshi, O. Matsuoka, S. Yamamoto, and H. Nozoye: Preparation of polyimide-polyamide random copolymer thin film by sequential vapor deposition polymerization. Jpn. J. Appl. Phys. 41, 746 (2002). 
64. P.W. Loscutoff, H.-B.-R. Lee, and S.F. Bent: Deposition of ultrathin polythiourea films by molecular layer deposition. Chem. Mater. 22, 5563-5569 (2010).

65. T.V. Ivanova, P.S. Maydannik, and D.C. Cameron: Molecular layer deposition of polyethylene terephthalate thin films. J. Vac. Sci. Technol. A 30, 01A121 (2012).

66. A.A. Dameron, D. Seghete, B.B. Burton, S.D. Davidson, A.S. Cavanagh, J.A. Bertrand, and S.M. George: Molecular layer deposition of alucone polymer films using trimethylaluminum and ethylene glycol. Chem. Mater. 20, 3315-3326 (2008).

67. B.H. Lee, V.R. Anderson, and S.M. George: Molecular layer deposition of zircone and $\mathrm{ZrO}_{2}$ /zircone alloy films: Growth and properties. Chem. Vapor Deposition 19, 204-212 (2013).

68. R.A. Hall, S.M. George, Y. Kim, W. Hwang, M.E. Samberg, N.A. Monteiro-Riviere, and R.J. Narayan: Growth of zircone on nanoporous alumina using molecular layer deposition. JOM 66, 649-653 (2014)

69. L.D. Salmi, M.J. Heikkilä, E. Puukilainen, T. Sajavaara,

D. Grosso, and M. Ritala: Studies on atomic layer deposition of MOF-5 thin films. Microporous Mesoporous Mater. 182, 147-154 (2013).

70. J.E. Crowell: Chemical methods of thin film deposition: Chemical vapor deposition, atomic layer deposition, and related technologies. J. Vac. Sci. Technol. A 21, S88-S95 (2003).

71. S.O. Kucheyev, J. Biener, Y.M. Wang, T.F. Baumann, K.J. Wu, T.v. Buuren, A.V. Hamza, J.H. Satcher Jr., J.W. Elam, and

M.J. Pellin: Atomic layer deposition of $\mathrm{ZnO}$ on ultralow-density nanoporous silica aerogel monoliths. Appl. Phys. Lett. 86, 083108 (2005).

72. M. Putkonen and L. Niinistö: Atomic layer deposition of $\mathrm{B}_{2} \mathrm{O}_{3}$ thin films at room temperature. Thin Solid Films 514, 145-149 (2006).

73. J. Cai, Z. Ma, U. Wejinya, M. Zou, Y. Liu, H. Zhou, and X. Meng: A revisit to atomic layer deposition of zinc oxide using diethylzinc and water as precursors. J. Mater. Sci. 54, 5236-5248 (2019).

74. R. Mikko and L. Markku: Atomic layer epitaxy - A valuable tool for nanotechnology? Nanotechnology 10, 19 (1999).

75. M. Knez, K. Nielsch, and L. Niinistö: Synthesis and surface engineering of complex nanostructures by atomic layer deposition. Adv. Mater. 19, 3425-3438 (2007).

76. X. Meng and J.W. Elam: Atomic layer deposition of nanophase materials for electrical energy storage. ECS Trans. 69, 39-57 (2015).

77. J.C. Badot, S. Ribes, E.B. Yousfi, V. Vivier, J.P. Pereira-Ramos, N. Baffier, and D. Lincot: Atomic layer epitaxy of vanadium oxide thin films and electrochemical behavior in presence of lithium ions. Electrochem. Solid State Lett. 3, 485-488 (2000).
78. M.Q. Snyder, S.A. Trebukhova, B. Ravdel, M.C. Wheeler, J. DiCarlo, C.P. Tripp, and W.J. DeSisto: Synthesis and characterization of atomic layer deposited titanium nitride thin films on lithium titanate spinel powder as a lithium-ion battery anode. J. Power Sources 165, 379-385 (2007).

79. S.W. Kim, T.H. Han, J. Kim, H. Gwon, H.S. Moon, S.W. Kang, S.O. Kim, and K. Kang: Fabrication and electrochemical characterization of $\mathrm{TiO}_{2}$ three-dimensional nanonetwork based on peptide assembly. ACS Nano 3, 1085-1090 (2009).

80. X. Meng, M.N. Banis, D. Geng, X. Li, Y. Zhang, R. Li, H. Abou-Rachid, and X. Sun: Controllable atomic layer deposition of one-dimensional nanotubular $\mathrm{TiO}_{2}$. Appl. Surface Sci. 266, 132-140 (2013)

81. X. Meng, D. Geng, J. Liu, R. Li, and X. Sun: Controllable synthesis of graphene-based titanium dioxide nanocomposites by atomic layer deposition. Nanotechnology 22, 165602 (2011).

82. X. Meng, Y. Zhang, S. Sun, R. Li, and X. Sun: Three growth modes and mechanisms for highly structure-tunable $\mathrm{SnO}_{2}$ nanotube arrays of template-directed atomic layer deposition. J. Mater. Chem. 21, 12321-12330 (2011).

83. X. Meng, Y. Zhong, Y. Sun, M.N. Banis, R. Li, and X. Sun: Nitrogen-doped carbon nanotubes coated by atomic layer deposited $\mathrm{SnO}_{2}$ with controlled morphology and phase. Carbon 49, 1133-1144 (2011)

84. X. Li, X. Meng, J. Liu, D. Geng, Y. Zhang, M.N. Banis, Y. Li, J. Yang, R. Li, X. Sun, M. Cai, and M.W. Verbrugge: Tin oxide with controlled morphology and crystallinity by atomic layer deposition onto graphene nanosheets for enhanced lithium storage. Adv. Funct. Mater. 22, 1647-1654 (2012).

85. X. Meng, D. Geng, J. Liu, M.N. Banis, Y. Zhang, R. Li, and X. Sun: Non-aqueous approach to synthesize amorphous/crystalline metal oxide-graphene nanosheet hybrid composites. J. Phys. Chem. C 114, 18330-18337 (2010).

86. X. Meng, J. Liu, X. Li, M.N. Banis, J. Yang, R. Li, and X. Sun: Atomic layer deposited $\mathrm{Li}_{4} \mathrm{Ti}_{5} \mathrm{O}_{12}$ on nitrogen-doped carbon nanotubes. RSC Adv. 3, 7285-7288 (2013).

87. S.C. Riha, A.A. Koegel, X. Meng, I.S. Kim, Y. Cao, M.J. Pellin, J.W. Elem, and A.B.F. Martinson: Atomic layer deposition of MnS: Phase control and electrochemical applications. ACS Appl. Mater. interfaces 8, 2774-2780 (2016).

88. X. Meng, K. He, D. Su, X. Zhang, C.J. Sun, Y. Ren, H.H. Wang, W. Weng, L. Trahey, C.P. Canlas, and J.W. Elam: Gallium sulfide-single-walled carbon nanotube composites:

High-performance anodes for lithium-ion batteries. Adv. Funct. Mater. 24, 5435-5442 (2014).

89. X. Meng, J.A. Libera, T.T. Fister, H. Zhou, J.K. Hedlund, P. Fenter, and J.W. Elam: Atomic layer deposition of gallium sulfide films using hexakis(dimethylamido)digallium and hydrogen sulfide. Chem. Mater. 26, 1029-1039 (2014). 
90. X. Meng, Y. Cao, J.A. Libera, and J.W. Elam: Atomic layer deposition of aluminum sulfide: Growth mechanism and electrochemical evaluation in lithium-ion batteries. Chem. Mater. 29, 9043-9052 (2017).

91. X. Chen, H. Zhu, Y.-C. Chen, Y. Shang, A. Cao, L. Hu, and G.W. Rubloff: MWCNT/ $\mathrm{V}_{2} \mathrm{O}_{5}$ core/shell sponge for high areal capacity and power density Li-ion cathodes. ACS Nano 6, 79487955 (2012)

92. J. Liu, M.N. Banis, Q. Sun, A. Lushington, R. Lu, T.-K. Sham, and X. Sun: Rational design of atomic-layer-deposited $\mathrm{LiFePO}_{4}$ as a high-performance cathode for lithium-ion batteries. $A d v$. Mater. 26, 6472-6477 (2014).

93. J. Liu, B. Xiao, M.N. Banis, R. Li, T.-K. Sham, and X. Sun: Atomic layer deposition of amorphous iron phosphates on carbon nanotubes as cathode materials for lithium-ion batteries. Electrochim. Acta 162, 275-281 (2015).

94. X. Meng, S.C. Riha, J.A. Libera, Q. Wu, H.-H. Wang, A.B.F. Martinson, and J.W. Elam: Tunable core-shell singlewalled carbon nanotube- $\mathrm{Cu}_{2} \mathrm{~S}$ networked nanocomposites as high-performance cathodes for lithium-ion batteries. J. Power Sources 280, 621-629 (2015).

95. M. Putkonen, T. Aaltonen, M. Alnes, T. Sajavaara, O. Nilsen, and H. Fjellvag: Atomic layer deposition of lithium containing thin films. J. Mater. Chem. 19, 8767-8771 (2009).

96. C. Liu, E.I. Gillette, X. Chen, A.J. Pearse, A.C. Kozen, M.A. Schroeder, K.E. Gregorczyk, S.B. Lee, and G.W. Rubloff: An all-in-one nanopore battery array. Nat Nano 9, 1031-1039 (2014).

97. A. Pearse, T. Schmitt, E. Sahadeo, D.M. Stewart, A. Kozen, K. Gerasopoulos, A.A. Talin, S.B. Lee, G.W. Rubloff, and K.E. Gregorczyk: Three-dimensional solid-state lithium-ion batteries fabricated by conformal vapor-phase chemistry. ACS Nano 12, 4286-4294 (2018).

98. Y.S. Jung, A.S. Cavanagh, A.C. Dillon, M.D. Groner, S.M. George, and S.H. Lee: Enhanced stability of $\mathrm{LiCoO}_{2}$ cathodes in lithium-ion batteries using surface modification by atomic layer deposition. J. Electrochem. Soc. 157, A75-A81 (2010).

99. Y.S. Jung, A.S. Cavanagh, L.A. Riley, S.H. Kang, A.C. Dillon, M.D. Groner, S.M. George, and S.H. Lee: Ultrathin direct atomic layer deposition on composite electrodes for highly durable and safe Li-ion batteries. Adv. Mater. 22, 2172-2176 (2010).

100. X. Li, J. Liu, X. Meng, Y. Tang, M.N. Banis, J. Yang, Y. Hu, R. Li, M. Cai, and X. Sun: Significant impact on cathode performance of lithium-ion batteries by precisely controlled metal oxide nanocoatings via atomic layer deposition. J. Power Sources 247, 57-69 (2014).

101. Y. Liu, X. Wang, J. Cai, X. Han, D. Geng, J. Li, and X. Meng: Atomic-scale tuned interface of nickel-rich cathode for enhanced electrochemical performance in lithium-ion batteries. J. Mater.

Sci. Technol. 54, 77-86 (2020).

102. H. Gao, J. Cai, G.-L. Xu, L. Li, Y. Ren, X. Meng, K. Amine, and

Z. Chen: Surface modification for suppressing interfacial parasitic reactions of a nickel-rich lithium-ion cathode. Chem. Mater. 31, 2723-2730 (2019).

103. J. Xie, A.D. Sendek, E.D. Cubuk, X. Zhang, Z. Lu, Y. Gong, T. Wu, F. Shi, W. Liu, E.J. Reed, and Y. Cui: Atomic layer deposition of stable $\mathrm{LiAlF}_{4}$ lithium ion conductive interfacial layer for stable cathode cycling. ACS Nano 11, 7019-7027 (2017).

104. A. Shapira, O. Tiurin, N. Solomatin, M. Auinat, A. Meitav, and Y. Ein-Eli: Robust $\mathrm{AlF}_{3}$ atomic layer deposition protective coating on $\mathrm{LiMn}_{1.5} \mathrm{Ni}_{0.5} \mathrm{O}_{4}$ particles: An advanced Li-ion battery cathode material powder. ACS Appl. Energy Mater. 1, 6809-6823 (2018).

105. Y. Cao, X. Meng, and J.W. Elam: Atomic layer deposition of $\mathrm{Li}_{x} \mathrm{Al}_{y} \mathrm{~S}$ solid-state electrolytes for stabilizing lithium-metal anodes. ChemElectroChem 3, 858-863 (2016).

106. B. Xiao, B. Wang, J. Liu, K. Kaliyappan, Q. Sun, Y. Liu, G. Dadheech, M.P. Balogh, L. Yang, T.-K. Sham, R. Li, M. Cai, and $X$. Sun: Highly stable $\mathrm{Li}_{1.2} \mathrm{Mn}_{0.54} \mathrm{Co}_{0.13} \mathrm{Ni}_{0.13} \mathrm{O}_{2}$ enabled by novel atomic layer deposited $\mathrm{AlPO}_{4}$ coating. Nano Energy 34, 120-130 (2017).

107. C.-F. Lin, X. Fan, A. Pearse, S.-C. Liou, K. Gregorczyk, M. Leskes, C. Wang, S.B. Lee, G.W. Rubloff, and M. Noked: Highly reversible conversion-type $\mathrm{FeOF}$ composite electrode with extended lithium insertion by atomic layer deposition LiPON protection. Chem. Mater. 29, 8780-8791 (2017).

108. H. Kim, J.T. Lee, D.C. Lee, A. Magasinski, W.I. Cho, and G. Yushin: Plasma-enhanced atomic layer deposition of ultrathin oxide coatings for stabilized lithium-sulfur batteries. Adv. Energy Mater. 3, 1308-1315 (2013).

109. X. Meng, D.J. Comstock, T.T. Fister, and J.W. Elam: Vapor-phase atomic-controllable growth of amorphous $\mathrm{Li}_{2} \mathrm{~S}$ for high-performance lithium-sulfur batteries. ACS Nano 8, 1096310972 (2014)

110. J. Lu, Y. Lei, K.C. Lau, X. Luo, P. Du, J. Wen, R.S. Assary, U. Das, D.J. Miller, J.W. Elam, H.M. Albishri, D.A. El-Hady, Y.-K. Sun, L.A. Curtiss, and K.A. Amine: A nanostructured cathode architecture for low charge overpotential in lithium-oxygen batteries. Nat. Commun. 4, 2383 (2013).

111. L. Zhao, J. Zhao, Y.-S. Hu, H. Li, Z. Zhou, M. Armand, and L. Chen: Disodium terephthalate $\left(\mathrm{Na}_{2} \mathrm{C}_{8} \mathrm{H}_{4} \mathrm{O}_{4}\right)$ as high performance anode material for low-cost room-temperature sodium-ion battery. Adv. Energy Mater. 2, 962-965 (2012).

112. N.D. Schuppert, S. Mukherjee, A.M. Bates, E.-J. Son, M.J. Choi, and S. Park: Ex-situ X-ray diffraction analysis of electrode strain at $\mathrm{TiO}_{2}$ atomic layer deposition/ $\alpha-\mathrm{MoO}_{3}$ 
interface in a novel aqueous potassium ion battery. J. Power Sources 316, 160-169 (2016).

113. K. Zhao, C. Wang, Y. Yu, M. Yan, Q. Wei, P. He, Y. Dong,

Z. Zhang, X. Wang, and L. Mai: Ultrathin surface coating enables stabilized zinc metal anode. Adv. Mater. Interfaces 5, 1800848 (2018).

114. D. Pal, A. Mathur, A. Singh, S. Pakhira, R. Singh, and S. Chattopadhyay: Binder-free $\mathrm{ZnO}$ cathode synthesized via ALD by direct growth of hierarchical $\mathrm{ZnO}$ nanostructure on current collector for high-performance rechargeable aluminium-ion batteries. ChemistrySelect 3, 12512-12523 (2018).

115. A.J. Loebl, C.J. Oldham, C.K. Devine, B. Gong, S.E. Atanasov, G.N. Parsons, and P.S. Fedkiw: Solid electrolyte interphase on lithium-ion carbon nanofiber electrodes by atomic and molecular layer deposition. J. Electrochem. Soc. 160, A1971A1978 (2013).

116. D.M. Piper, J.J. Travis, M. Young, S.-B. Son, S.C. Kim, K.H. Oh, S.M. George, C. Ban, and S.-H. Lee: Reversible high-capacity Si nanocomposite anodes for lithium-ion batteries enabled by molecular layer deposition. Adv. Mater. 26, 15961601 (2014).

117. Y. Zhao, L.V. Goncharova, Q. Sun, X. Li, A. Lushington,

B. Wang, R. Li, F. Dai, M. Cai, and X. Sun: Robust metallic lithium anode protection by the molecular-layer-deposition technique. Small Methods 2, 1700417 (2018).

118. Y. Zhao, L.V. Goncharova, Q. Zhang, P. Kaghazchi, Q. Sun, A. Lushington, B. Wang, R. Li, and X. Sun: Inorganic-organic coating via molecular layer deposition enables long life sodium metal anode. Nano Lett. 17, 5653-5659 (2017).

119. K. Kaliyappan, T. Or, Y.-P. Deng, Y. Hu, Z. Bai, and Z. Chen: Constructing safe and durable high-voltage P2 layered cathodes for sodium ion batteries enabled by molecular layer deposition of alucone. Adv. Funct. Mater. 30, 1910251 (2020).

120. M. Nisula and M. Karppinen: Atomic/molecular layer deposition of lithium terephthalate thin films as high rate capability Li-ion battery anodes. Nano Lett. 16, 1276-1281 (2016).

121. C. Ban and S.M. George: Molecular layer deposition for surface modification of lithium-ion battery electrodes. Adv. Mater. Interfaces 3, 1600762 (2016).

122. X. Meng, X. Wang, D. Geng, C. Ozgit-Akgun, N. Schneider, and J.W. Elam: Atomic layer deposition for nanomaterial synthesis and functionalization in energy technology. Mater. Horizons 4, 133-154 (2017).

123. Y. Zhao, K. Zheng, and $X$. Sun: addressing interfacial issues in liquid-based and solid-state batteries by atomic and molecular layer deposition. Joule 2, 2583-2604 (2018).

124. M.S. Whittingham: Ultimate limits to intercalation reactions for lithium batteries. Chem. Rev. 114, 11414-11443 (2014).
125. M.S. Whittingham: Lithium batteries and cathode materials. Chem. Rev. 104, 4271-4302 (2004).

126. M.R. Zamfir, H.T. Nguyen, E. Moyen, Y.H. Lee, and D. Pribat: Silicon nanowires for Li-based battery anodes: A review. J. Mater. Chem. A 1, 9566-9586 (2013).

127. C.-M. Park, J.-H. Kim, H. Kim, and H.-J. Sohn: Li-alloy based anode materials for Li secondary batteries. Chem. Soc. Rev. 39 3115-3141 (2010).

128. J.M. Wallas, B.C. Welch, Y. Wang, J. Liu, S.E. Hafner, R. Qiao, T. Yoon, Y.-T. Cheng, S.M. George, and C. Ban: Spatial molecular layer deposition of ultrathin polyamide to stabilize silicon anodes in lithium-ion batteries. ACS Appl. Energy Mater. 2, 4135-4143 (2019).

129. J. Ma, P. Hu, G. Cui, and L. Chen: Surface and interface issues in spinel $\mathrm{LiNi}_{0.5} \mathrm{Mn}_{1.5} \mathrm{O}_{4}$ : Insights into a potential cathode material for high energy density lithium ion batteries. Chem. Mater. 28, 3578-3606 (2016).

130. J.S. Park, X. Meng, J.W. Elam, S. Hao, C. Wolverton, C. Kim, and J. Cabana: Ultrathin lithium-ion conducting coatings for increased interfacial stability in high voltage lithium-ion batteries. Chem. Mater. 26, 3128-3134 (2014).

131. O. Tiurin, N. Solomatin, M. Auinat, and Y. Ein-Eli: Atomic layer deposition (ALD) of lithium fluoride (LiF) protective film on Li-ion battery $\mathrm{LiMn}_{1.5} \mathrm{Ni}_{0.5} \mathrm{O}_{4}$ cathode powder material. J. Power Sources 448, 227373 (2020).

132. S. Chae, J. Soon, H. Jeong, T.j. Lee, J.H. Ryu, and S.M. Oh: Passivating film artificially built on $\mathrm{LiNi}_{0.5} \mathrm{Mn}_{1.5} \mathrm{O}_{4}$ by molecular layer deposition of (pentafluorophenylpropyl)trimethoxysilane. J. Power Sources 392, 159-167 (2018).

133. P.K. Nayak, E.M. Erickson, F. Schipper, T.R. Penki, N. Munichandraiah, P. Adelhelm, H. Sclar, F. Amalraj, B. Markovsky, and D. Aurbach: Review on challenges and recent advances in the electrochemical performance of high capacity Liand Mn-rich cathode materials for Li-Ion batteries. Adv. Energy Mater. 8, 1702397 (2018).

134. X. Zhang, X. Meng, J.W. Elam, and I. Belharouak: Electrochemical characterization of voltage fade of $\mathrm{Li}_{1.2} \mathrm{Ni}_{0.2} \mathrm{Mn}_{0.6} \mathrm{O}_{2}$ cathode. Solid State Ionics 268, 231-235 (2014).

135. I. Bloom, L. Trahey, A. Abouimrane, I. Belharouak, X. Zhang, Q. Wu, W. Lu, D.P. Abraham, M. Bettge, J.W. Elam, X. Meng, A.K. Burrell, C. Ban, R. Tenent, J. Nanda, and N. Dudney: Effect of interface modifications on voltage fade in $0.5 \mathrm{Li}_{2} \mathrm{MnO}_{3} \cdot 0.5 \mathrm{LiNi}_{0.375} \mathrm{Mn}_{0.375} \mathrm{CO}_{0.25} \mathrm{O}_{2}$ cathode materials. J. Power Sources 249, 509-514 (2014).

136. H. Pan, S. Zhang, J. Chen, M. Gao, Y. Liu, T. Zhu, and Y. Jiang: Li- and Mn-rich layered oxide cathode materials for lithium-ion batteries: A review from fundamentals to research progress and applications. Mol. Syst. Design Eng. 3, 748-803 (2018). 
137. Y. Gao, Z. Shang, X. He, T. White, J. Park, and X. Liang: Cooperating effects of conformal iron oxide ( $\mathrm{FeOx}$ ) ALD coating and post-annealing on Li-Rich layered cathode materials. Electrochim. Acta 318, 513-524 (2019).

138. A.L. Hoskins, W.W. McNeary, S.L. Millican, T.A. Gossett, A. Lai, Y. Gao, X. Liang, C.B. Musgrave, and A.W. Weimer: Nonuniform growth of sub-2 nanometer atomic layer deposited alumina films on lithium nickel manganese cobalt oxide cathode battery materials. ACS Appl. Nano Mater. 2, 6989-6997 (2019).

139. Y. Liu, X. Wang, J. Cai, X. Han, D. Geng, J. Li, and X. Meng: Atomic-scale tuned interface of nickel-rich cathode for enhanced electrochemical performance in lithium-ion batteries. J. Mater. Sci. Technol. 54, 77-86 (2020).

140. P. Yan, J. Zheng, J. Liu, B. Wang, X. Cheng, Y. Zhang, X. Sun, C. Wang, and J.-G. Zhang: Tailoring grain boundary structures and chemistry of Ni-rich layered cathodes for enhanced cycle stability of lithium-ion batteries. Nat. Energy 3, 600-605 (2018).

141. X. Cheng, J. Zheng, J. Lu, Y. Li, P. Yan, and Y. Zhang: Realizing superior cycling stability of Ni-rich layered cathode by combination of grain boundary engineering and surface coating. Nano Energy 62, 30-37 (2019).

142. X. Li, J. Liu, M.N. Banis, A. Lushington, R. Li, M. Cai, and X. Sun: Atomic layer deposition of solid-state electrolyte coated cathode materials with superior high-voltage cycling behavior for lithium ion battery application. Energy Environ. Sci. 7, 768-778 (2014).

143. J. Yang, D. Ma, Y. Li, P. Zhang, H. Mi, L. Deng, L. Sun, and $\mathrm{X}$. Ren: Atomic layer deposition of amorphous oxygen-deficient $\mathrm{TiO}_{2-\mathrm{x}}$ on carbon nanotubes as cathode materials for lithium-air batteries. J. Power Sources 360, 215-220 (2017).

144. C. Gong, L. Zhao, S. Li, H. Wang, Y. Gong, R. Wang, and

B. He: Atomic layered deposition iron oxide on perovskite $\mathrm{LaNiO}_{3}$ as an efficient and robust bi-functional catalyst for lithium oxygen batteries. Electrochim. Acta 281, 338-347 (2018).

145. W. Xu, J. Wang, F. Ding, X. Chen, E. Nasybulin, Y. Zhang, and J.-G. Zhang: Lithium metal anodes for rechargeable batteries. Energy Environ. Sci. 7, 513-537 (2014).

146. A.C. Kozen, C.-F. Lin, A.J. Pearse, M.A. Schroeder, X. Han, L. Hu, S.-B. Lee, G.W. Rubloff, and M. Noked: Next-generation lithium metal anode engineering via atomic layer deposition. ACS Nano 9, 5884-5892 (2015).

147. E. Kazyak, K.N. Wood, and N.P. Dasgupta: Improved cycle life and stability of lithium metal anodes through ultrathin atomic layer deposition surface treatments. Chem. Mater. 27, 6457-6462 (2015).

148. C.-F. Lin, A.C. Kozen, M. Noked, C. Liu, and G.W. Rubloff ALD protection of Li-metal anode surfaces - Quantifying and preventing chemical and electrochemical corrosion in organic solvent. Adv. Mater. Interfaces 3, 1600426 (2016).

149. K.L. Harrison, K.R. Zavadil, N.T. Hahn, X. Meng, J.W. Elam, A. Leenheer, J.-G. Zhang, and K.L. Jungjohann: Lithium selfdischarge and its prevention: Direct visualization through in situ electrochemical scanning transmission electron microscopy. ACS Nano 11, 11194-11205 (2017).

150. K.R. Adair, C. Zhao, M.N. Banis, Y. Zhao, R. Li, M. Cai, and X. Sun: Highly stable lithium metal anode interface via molecular layer deposition zircone coatings for long life next-generation battery systems. Angew. Chem. Int. Ed. 58, 15797-15802 (2019).

151. Y. Sun, Y. Zhao, J. Wang, J. Liang, C. Wang, Q. Sun, X. Lin, K.R. Adair, J. Luo, D. Wang, R. Li, M. Cai, T.-K. Sham, and X. Sun: A novel organic "Polyurea" thin film for ultralong-life lithium-metal anodes via molecular-layer deposition. Adv. Mater. 31, 1806541 (2019).

152. Y. Zhao, M. Amirmaleki, Q. Sun, C. Zhao, A. Codirenzi, L.V. Goncharova, C. Wang, K. Adair, X. Li, X. Yang, F. Zhao, R. Li, T. Filleter, M. Cai, and X. Sun: Natural SEI-inspired dual-protective layers via atomic/molecular layer deposition for long-life metallic lithium anode. Matter 1, 1215-1231 (2019).

153. M.E. Donders, H.C.M. Knoops, W.M.M. Kessels, and P.H.L. Notten: Remote plasma atomic layer deposition of thin films of electrochemically active $\mathrm{LiCoO}_{2}$. ECS Trans. 41, 321-330 (2011).

154. K.B. Gandrud, A. Pettersen, O. Nilsen, and H. Fjellvag: High-performing iron phosphate for enhanced lithium ion solid state batteries as grown by atomic layer deposition. J. Mater. Chem. A 1, 9054-9059 (2013).

155. V. Miikkulainen, A. Ruud, E. Ostreng, O. Nilsen, M. Laitinen, T. Sajavaara, and H. Fjellvag: Atomic layer deposition of spinel lithium manganese oxide by film-body-controlled lithium incorporation for thin-film lithium-ion batteries. J. Phys. Chem. C 118, 1258-1268 (2014).

156. J.-F. Chen, X.-D. He, D.-J. Li, and J.-M. Feng: Improved potassium ion storage performance of graphite by atomic layer deposition of aluminum oxide coatings. Int. J. Energy Res. 44, 4260-4268 (2020).

157. J. Su, T. Tsuruoka, T. Tsujita, Y. Nishitani, K. Nakura, and K. Terabe: Atomic layer deposition of a magnesium phosphate solid electrolyte. Chem. Mater. 31, 5566-5575 (2019). 